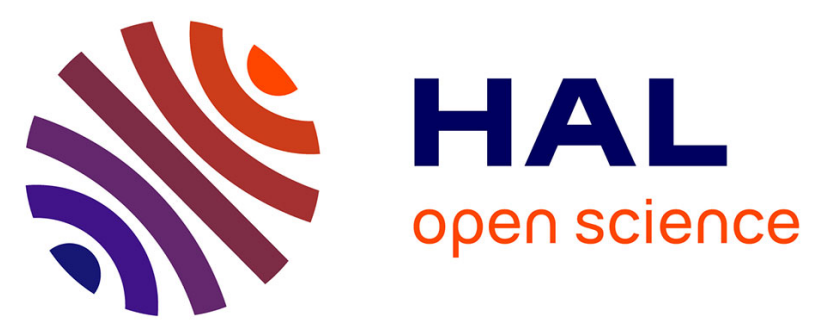

\title{
Association Between Layer-Specific Longitudinal Strain and Risk Factors of Heart Failure and Dyspnea: A Population-Based Study
}

Olivier Huttin, Nicolas Girerd, Stefano Coiro, Erwan Bozec, Christine Selton-Suty, Zohra Lamiral, Zied Frikha, Masatake Kobayashi, Edgar Argulian, Jagat Narula, et al.

\section{To cite this version:}

Olivier Huttin, Nicolas Girerd, Stefano Coiro, Erwan Bozec, Christine Selton-Suty, et al.. Association Between Layer-Specific Longitudinal Strain and Risk Factors of Heart Failure and Dyspnea: A Population-Based Study. Journal of The American Society of Echocardiography, 2019, 32 (7), pp.854-865. 10.1016/j.echo.2019.03.011 . hal-03487208

\section{HAL Id: hal-03487208 \\ https://hal.science/hal-03487208}

Submitted on 20 Dec 2021

HAL is a multi-disciplinary open access archive for the deposit and dissemination of scientific research documents, whether they are published or not. The documents may come from teaching and research institutions in France or abroad, or from public or private research centers.
L'archive ouverte pluridisciplinaire HAL, est destinée au dépôt et à la diffusion de documents scientifiques de niveau recherche, publiés ou non, émanant des établissements d'enseignement et de recherche français ou étrangers, des laboratoires publics ou privés.

\section{(ㅇ)(1) $\$$}

Distributed under a Creative Commons Attribution - NonCommerciall 4.0 International 


\section{ASSOCIATION BETWEEN LAYER-SPECIFIC}

\section{LONGITUDINAL STRAIN AND RISK FACTORS OF}

\section{HEART FAILURE AND DYSPNEA: A POPULATION-}

\section{BASED STUDY}

SHORT TITLE: Layer-specific myocardial deformation and dyspnea

Olivier Huttin ${ }^{1,3}$ MD, PhD; Nicolas Girerd ${ }^{1 *}$ MD, PhD; Stefano Coiro ${ }^{1,2}$ MD, MSc; Erwan Bozec ${ }^{1} \mathrm{PhD}$; Christine Selton-Suty ${ }^{3}$ MD; Zohra Lamiral ${ }^{1}$ Msc; Zied Frikha MD ${ }^{1}$; Masatake Kobayashi ${ }^{1}$ MD, MSc; Edgar Argulian ${ }^{5}$ MD, MPH; Jagat Narula ${ }^{5}$ MD, PhD; Alan G Fraser ${ }^{4}$ MD, PhD; Patrick Rossignol ${ }^{1}$ MD, PhD; Faiez Zannad ${ }^{1}$ MD, PhD

${ }^{1}$ Inserm, Centre d'Investigations Cliniques- Plurithématique 14-33, Inserm U1116, CHRU Nancy, Université de Lorraine, and F-CRIN INI-CRCT (Cardiovascular and Renal Clinical Trialists), Nancy, France

${ }^{2}$ Division of Cardiology, University of Perugia, Ospedale S. Maria della Misericordia, Perugia, Italy

${ }^{3}$ Service de Cardiologie, Institut Lorrain du Cœur et des Vaisseaux, Centre Hospitalier Universitaire de Nancy

4 School of Medicine, Cardiff University, Cardiff, UK.

${ }^{5}$ Icahn School of Medicine at Mount Sinai, New York, NY

* Corresponding author. INSERM CHU de Nancy, Institut Lorrain du Cœur et des Vaisseaux Louis Mathieu, 4 Rue du Morvan, 54500 Vandoeuvre lès Nancy, France; Tel: +33 38315 74 96, Fax: +33 3 831573 24, Email: nicolas_girerd@yahoo.com 


\section{ABSTRACT}

BACKGROUND Global longitudinal strain (GLS), derived from speckle tracking echocardiography (STE), is a widely-used and reproducible left ventricular deformation parameter; assessment of multilayer strain components has also become possible. However, its association with comorbidities/symptoms in low-risk populations without cardiac disease remains understudied.

OBJECTIVES We report reference ranges for longitudinal deformation and their association with cardiovascular risk factors and dyspnea in a large population-based cohort.

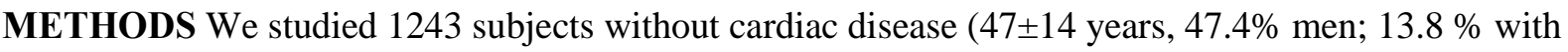
dyspnea) enrolled in the $4^{\text {th }}$ visit of the STANISLAS Cohort (Lorraine, France). Clinical evaluation included a comprehensive dyspnea questionnaire. Multilayer GLS (full-wall, subendocardial and subepicardial) and strain rate (systolic, early and late diastolic) were evaluated by GLS STE acquisition and measurement protocols as per recommendations by the EACVI/ASE/Industry Task Force.

RESULTS Full-wall GLS was $23.4 \pm 2.7 \%($ mean \pm SD) with a subendocardial/subepicardial ratio of 1.2 \pm 0.1 . Age, gender, smoking status and BMI were significantly associated with strain variables whereas diabetes, dyslipidemia and hypertension/systolic blood pressure were not. Specifically, there were reductions in diastolic strain rate with aging but no differences in GLS. After propensity-score matching, subjects with dyspnea had lower global endocardial strain (-23.48 \pm 2.70 vs. $-23.02 \pm 2.81$; $\mathrm{P}=0.043)$ and lower global subendocardial/subepicardial strain ratio $(\mathrm{P}=0.034)$, whereas transmural strain and classical echocardiographic measurements were unrelated to dyspnea.

CONCLUSIONS Higher BMI was found significantly associated with impaired strain variables in a low-risk population without cardiac disease. In addition, lower global endocardial strain and lower global subendocardial/subepicardial strain ratio were significantly associated with dyspnea contrary to other echocardiographic variables.

Keywords: Myocardial deformation, Left ventricle, Systolic function, Speckle-tracking echocardiography Population study, Reference values, Dyspnea 


\section{HIGHLIGHTS}

- This study provides normal ranges for global longitudinal strain, along with multilayer and diastolic myocardial deformation parameters.

- Higher BMI was significantly associated with impaired strain in multivariable models in our cohort without heart disease.

- In this large population of subjects without cardiac disease, an association between layerspecific strain variables and self-reported dyspnea was documented whereas other echocardiographic measurements were not. 


\section{ABBREVIATIONS}

GLS: Peak longitudinal strain

GSR: Global strain rate

GSendo: Global subendocardial GLS

GSepi: Global subepicardial GLS

cohort without heart disease.

GSfull-wall: Global full-wall GLS

- In this large population of subjects without cardiac disease, an association between layer-

specific strain variables and self-reported dyspnea was documented whereas other

echocardiographic measurements were not. 


\section{INTRODUCTION}

Phenotyping heart failure (HF), whether at a preclinical stage or after onset of the disease, represents a major challenge for research and clinical practice. It would thus be of particular interest to identify patients at risk of progression to overt $\mathrm{HF}$ with preserved ejection fraction (HfpEF) in addition to determining therapeutic targets where appropriate treatment could potentially delay its onset.

Speckle-tracking echocardiography (STE) enables quantitative assessment of myocardial function through image-based analysis of myocardial deformation (1). Normal values for global longitudinal strain (GLS) have previously been published (2)(3). The EACVI/ASE/Industry Task Force recognized good reproducibility of GLS between vendors which was deemed better than with conventional echocardiographic measurements (4). (5). Spatial heterogeneity of myocardial deformation including base-to-apex (6) and transmural gradients of strain has triggered the development of methods for the assessment of layer-specific myocardial strain. Improved software now allows multiple measurements and comprehensive analysis of longitudinal myocardial deformation from the 3 standard apical views. A simple 3-step post-processing enables yielding: multi-layer spatial (endocardial, epicardial) and fullwall strain as well as global systolic and diastolic strain rates.

These measurements of myocardial deformation can be influenced by clinical variables such as hemodynamic factors and cardiovascular aging, even in the absence of pathological conditions (2). In the setting of preclinical diastolic dysfunction, dyspnea is typically an early warning sign even in subjects with no established structural heart or lung diseases (7). Age-related cardiovascular changes in combination with risk factors can result in altered left ventricular systolic and/or diastolic deformation as well as vascular stiffening manifesting as dyspnea; these early changes may moreover not be captured by traditional echocardiographic parameters.

In light of the above, the present large population study aimed to: i) provide normal range values for myocardial deformation parameters and ii) evaluate the association between clinical and echocardiographic variables (including layer-specific strain) and the self-reported symptom of dyspnea. 


\section{METHODS}

\section{Study population}

The STANISLAS Cohort is a single-center familial longitudinal cohort which includes 1006 families (4295 subjects) from the Nancy region of France recruited in 1993-1995 at the Center for Preventive Medicine. The families were deemed healthy, and free of declared acute and/or chronic illnesses, in order to assess the effect of genetic variability of intermediate phenotypes on the transition toward disease. Patients who were previously diagnosed with HF, coronary artery disease or with more than moderate valvular heart disease were excluded from the analysis. Patients with other potential causes of dyspnea such as significant lung disease by spirometry were also excluded. From 2011 to 2015, a total of 1293 subjects aged 20 to 75 years with no evidence of cardiac disease, drawn from survivors of the original cohort, underwent their 4th examination using high-quality echocardiographic imaging at our department. After exclusions, a total of 1243 men and women had a comprehensive strain analysis. The research protocol was approved by the local Ethics Committee (CPP Est) and all study participants gave their written informed consent.

\section{Clinical evaluation}

Clinical evaluation included information regarding past medical history, symptoms suggestive of any cardiovascular disease, anthropometric measurements (height, weight, and waist circumference), and general physical examination (including blood pressure measurement). Subjects with dyspnea were identified using a comprehensive questionnaire and if they answered 'yes' to at least one of the following standardized questions: Do you become abnormally short of breath? Do you feel short of breath at rest in a seated position?; Do you experience shortness of breath on minimal effort during your normal daily life?.

\section{D echocardiography}


Echocardiographic examinations were performed and centralized in a central core laboratory at the University Hospital of Nancy using standard commercially available ultrasound equipment (Vivid 9, General Electric Medical Systems, Horten, Norway) with a 2.5MHz phased-array transducer (M5S). Echocardiographic images were obtained from the 3 standard left ventricular (LV) apical views (4-, 2and 3-chambers). All images were acquired at 50 to 70 frames per second and at least three consecutive cardiac cycles were stored for analysis.

\section{Post-processing analysis of deformation parameters}

All strain measurements were performed offline by 2 experienced echocardiographers $(\mathrm{OH}, \mathrm{SC})$ with dedicated automated software (Q analysis software, Echo PAC PC version 110.1.0, GE Healthcare). The software allows generating LV strain curves, with one corresponding to each myocardial segment (Figure 1). Timing of end-systole was defined by the software as the lowest cavity size immediately before aortic valve closure (AVC) on the apical 3-chamber view. For multi-layer analysis, the total myocardial thickness (equivalent to full-wall strain) was divided by multiple chains of nodes into two myocardial layers of similar thickness from the endocardium to the epicardium: an endocardial layer and an epicardial layer. Tracking feasibility in each apical view was rated by visual inspection. All echocardiographic studies with suboptimal images and/or moderate to poor tracking quality $(n=415)$ were reviewed by a second senior echocardiographer. Segments or views with persistent poor tracking quality were excluded (Table S3). Values retrieved following analysis by this second senior echocardiographer were retained in the subsequent analysis. Reproducibility was similar for all three layers (intra- and inter-observer ICC were >0.80). (8)

\section{Strain parameters}

The following systolic left ventricular deformation parameters were obtained from 3 apical views: a) global subendocardial GLS (GSendo); b) global full-wall GLS (GSfull-wall) and c) global subepicardial GLS (GSepi) (Figure 1). In addition, systolic global strain rate (GSRs), as well as early (GSRe) and late (GSRa) diastolic strain rates were automatically displayed and calculated from the average of all 17 segments (Figure 2). 
As recommended, strain changes were considered using the absolute value of the number (i.e. an increase in GLS signifying that the number is becoming increasingly negative).

\section{Statistical methods}

All analyses were performed using SAS 9.4. The two-tailed significance level was set at $\mathrm{p}<0.05$. Continuous variables are described as means \pm standard deviation, and categorical variables as frequencies (percentages). Comparisons of baseline characteristics according to dyspnea or gender were carried out using either the Mann-Whitney test or t-test for continuous variables and chi-square or Fisher's exact test for categorical variables. Comparisons of continuous variables according to age categories were performed using either the Kruskal-Wallis test with post-test Dunn correction or oneway ANOVA with post-hoc tests using the Bonferroni correction. Relationships between strain and independent factors among age, gender, smoking status, diabetes, BMI, hypertension, dyslipidemia, dyspnea, systolic blood pressure, heart rate and LV hypertrophy (LVH) were assessed using multiple linear regression models.

We next investigated the association between strain variables and dyspnea. In order to correct for potential bias, a propensity score (PS)-based analysis was performed. The PS representing the a priori likelihood of having dyspnea was calculated for each patient using a logistic regression model. An inverse probability treatment weighting (IPTW) was then performed using stabilized weights. The balance between the two groups (dyspnea vs. no dyspnea) was assessed using absolute standardized mean differences. For each variable, the absolute standardized mean difference represents the absolute difference between the mean values in the two groups divided by the common standard deviation.

\section{RESULTS}

\section{Clinical and non-strain echocardiographic data}

Table 1 summarizes the demographic data obtained in the entire population as well as according to age subsets and gender. On average, subjects were middle-aged (48 \pm 14 years) and overweight (BMI $25 \pm 4$ $\left.\mathrm{mg} / \mathrm{m}^{2}\right)$. About one fifth (23\%) were current smokers and $16.3 \%$ had self-reported hypertension or were 
on anti-hypertensive medication. There were differences in baseline characteristics according to gender

(Table 1), with men being older and exhibiting higher blood pressure and glucose levels compared to women. One hundred seventy-two (13.8\%) subjects had dyspnea, with a minority of patients having severe dyspnea ( 3 participants felt short of breath at rest in a seated position and 13 had shortness of breath on minimal effort during normal daily activities). Left ventricular systolic and diastolic function according to dyspnea status is presented in Table 2 .

\section{Reference ranges of multilayer global peak systolic longitudinal strain and strain rate in the whole cohort and in subsets according to age and gender}

In the whole cohort, the absolute mean value of full-wall global longitudinal strain (GSfull-wall) was $21.1 \pm 2.5 \%$ (Table S2). The absolute mean value for GSendo was $23.4 \pm 2.7 \%$ and $19.1 \pm 2.5 \%$ for GSepi with a GSendo/GSepi ratio of $1.2 \pm 0.0 \%$. Absolute GS values were higher in the apical segments compared to the basal segments, especially in the subendocardium. GSendo \%, GSfull-wall \% and GSepi \% were all significantly higher in women and in older subjects (Figure 3, Table S2 and S3).

The absolute mean values of GSRs, GSRe and GSRa were $1.12 \pm 0.17 \mathrm{~s}^{-1}, 1.38 \pm 0.39 \mathrm{~s}^{-1}$ and $0.86 \pm 0.25 \mathrm{~s}^{-}$

${ }^{1}$, respectively. GSRe was higher in women than in men and progressively decreased with age while GSRa progressively increased (Table S2 and S3).

In the subset of patients without risk factors $(\mathrm{N}=441)$, the absolute mean value was $21.5 \pm 2.4 \%$ for GSfull-wall, $23.8 \pm 2.6 \%$ for GSendo and $19.4 \pm 2.4 \%$ for GSepi. The mean GSendo/GSepi ratio was $1.23 \pm 0.08$

\section{Association between common, cardiovascular risk factor and deformation variables}

Patients were divided into three groups according to the ACC/AHA classification of HF (stage 0/A/B according to clinical risk factors and cardiac structural/functional abnormalities, Table S8). The differences in classical echocardiographic parameters were intrinsically large across groups with a decrease in all deformation parameters in relation to the severity of the HF stage. In a multivariable linear model adjusted for LV mass, each $1 \mathrm{~kg} / \mathrm{m}^{2}$ increment in BMI was significantly associated with a significant 
decrease of all GS and GSR values including a $0.11 \pm 0.02 \%$ decrease in GSendo $(\mathrm{p}<0.0001)$ (Table 3). In contrast, higher age and female gender were significantly associated with an increase in all GS variables (Table 3). Specifically, when considering age as a continuous linear variable, a significant association between age and full-wall GLS was identified even after adjustment for confounding factors $(\beta$ for age $($ per $10 \mathrm{yr}$ increment $)=-0.03 \pm 0.01 ; \mathrm{p}<0.0001)$. Hypertension was not significantly associated with strain variables whereas diabetes was only significantly associated with GSRe. Systolic blood pressure was significantly associated with GSepi but not with GSendo or GSfull-wall.

Of note, dyspnea was significantly associated with both GSendo and GSRs in the above models but not with other strain components (Table 4).

\section{Left ventricular deformation parameters according to dyspnea}

Substantial differences in baseline characteristics were observed between the groups of patients with and without dyspnea (Table S1). As expected, patients with dyspnea were older, more likely to be overweight and had a higher heart rate as well as carried a higher burden of hypertension and dyslipidemia. After application of IPTW, the standardized differences were reduced to less than 10\% for all characteristics demonstrating substantial improvement of the balance across the dyspnea groups. Moreover, no significant differences were observed in LV systolic and diastolic function parameters except for tricuspid regurgitant velocity (reliable tricuspid regurgitation jet was unobtainable in more than one-third of the subjects) (Table 2).

In unweighted analyses, dyspnea groups differed in most of the strain variables including GSendo and GSendo/GSepi ratio. In IPTW analysis, accounting for PS, differences remained significant for GSendo $\%$ and GSendo/GSepi ratio. GSendo was lower in patients with dyspnea comparatively to those without dyspnea $(-23.48 \pm 2.70$ vs. $-23.02 \pm 2.81 ; \mathrm{P}=0.043)$ along with a lower GSendo/ GSepi ratio ( $\mathrm{p}=0.034)$ (table 4). 


\section{DISCUSSION}

In the present study, we used 2D speckle tracking to systematically measure myocardial deformation in a large population (to our knowledge the largest published to date) in order to establish reference ranges for multiple parameters of longitudinal function. Our results confirmed the need to interpret these deformation data according to age and gender. In addition, to the best of our knowledge, the present analysis is the first to provide evidence for an association between, a strain variable and self-reported dyspnea in patients without overt heart failure. Self-reported dyspnea appears as an interesting outcome in this context as it is likely to be a symptom related to early-stage HFpEF. Among various echocardiographic measurements, multilayer strain may be the earliest parameter to show an association with clinical features.

\section{Full-wall global peak systolic longitudinal strain}

Full-wall (or transmural) GLS, also called global longitudinal strain, is the most commonly used deformation parameter. The EACVI/ASE/Industry Task Force established standard definitions and methods for calculating deformation indices (5). A head-to head comparison of global strain values between vendors demonstrated absolute values ranging from 18.0 to $21.5 \%$ along with an absolute difference of up to $3.7 \%$ units (4). Previous studies reported normal GLS values from relatively small populations, mostly recruiting patients with "normal" echocardiographic findings while only a few studies recruited a large number of healthy individuals from the community. A large meta-analysis published in 2010 identified 2,597 subjects from 24 studies (3), in which normal GLS values varied from $-15.9 \%$ to $-22.1 \%$ with a mean value of $-19.7 \%$. Blood pressure, but not age, gender, frame rate or equipment, was associated with variations in normal GLS values. Another large study of 1266 healthy individuals proposed $-18.6 \pm 0.1 \%$ as an average normal value (9). In this latter study, which is the largest echocardiographic dataset with detailed strain analysis published to date, all echocardiographic examinations were performed with the same ultrasound system (Vivid 7 scanner - BT06). In the present study, using newer versions of both ultrasound machine and software (Vivid 9, BT 13), the absolute 
mean value was higher at $-21.1 \pm 2.5 \%$. Consistent with other reports, the absolute mean values were higher in women but showed no significant change according to different age groups (2)(3).

\section{STE-derived strain rate}

Strain, initially described as an analog of regional ejection fraction, has been criticized for having high load-dependence. Strain rate is a parameter that is well correlated with the rate of change in LV pressure and appears to better reflect contractility and to be less load-dependent than strain. It is best measured at high temporal resolution, hence is usually evaluated by tissue Doppler imaging (TDI), although it can also be measured using 2D STE. In the present study, GSR values were similar to previously-reported normal GSR values measured by STE (9). While it has been suggested that strain rate measurements obtained from 2D STE may be less accurate, our observations showed a very high reproducibility, almost equivalent to TDI measurements both in systole and diastole (8). Thus, we report normal values for an ultrasound parameter that may become standard. STE-SR derived E/E' (E/e'sR) may be a robust surrogate marker of elevated LV filling pressure. [22]

\section{Layer-specific strain}

One of the major achievements of speckle tracking is its ability to track the entire myocardium for quantitative assessment. In normal subjects, longitudinal strain increases from base to apex, whereas transverse strain decreases from base to apex (6). However, it is only recently that conventional software has been able to provide information regarding the transmural spatial distribution of GLS. Longitudinal fibers of the LV are mainly located in the subendocardium and are commonly affected early during myocardial disease. We observed a base/apex ratio of $0.82 \pm 0.13$ for GSfull-wall, with this ratio being less pronounced for epicardial layers comparatively to the endocardial layer. A previous study showed that longitudinal strain was higher in the endocardium and lower in the epicardium, with endocardial and mid-wall layer strain being higher in the apex and lower in the base (6). Previous studies have proposed normal reference values in healthy subjects for layer-specific strain based on both 
age and gender (12). In the present study, this multilayer longitudinal STE gradient was approximately $20 \%$ (GSendo /GSepi ratio $=1.2 \pm 0.1$ ). Since fiber direction varies across the cardiac wall, longitudinal tension can also vary depending on the layer and the loading condition as well as the degree of LV hypertrophy. Differences among layers are of clinical interest and therefore require a sensitive and reproducible tool to be detected. Depending on the disease, the myocardium can exhibit a specific impairment of subendocardial function (ischemic disease) or subepicardial dysfunction (myopericarditis). Layer-specific strain measurements can be useful to detect myocardial ischemia (13), guide etiological diagnosis of left ventricular hypertrophy (14) and detect early abnormalities of systolic function (15). The present results provide for the first time a sound estimation of normal values in a large population-based sample of patients.

\section{Association of cardiovascular risk factors with strain}

Significant age-related reductions in deformation have been reported (e.g., GLS [GE] of -20.3\% in healthy subjects over 60 years of age versus 22.1 in those $<20$ years in a cohort reported by Zghal et al. (16)). Some of these measurements show that clinical covariates contributed to only a modest proportion of the variation in strain values (17).Our data provide normal reference values of layerspecific longitudinal strain for age subsets although we did not identify significant differences in strain between subjects $>60$ years and patients between $20-40$ years of age. However, when considering age as a continuous linear variable, a significant association between age and GLS, GSendo and GSepi was documented (i.e.: GS Full-wall and age (per 10 yr increment) $\beta=-0.03 \pm 0.01 ; p<0.0001$ ) after adjustment for confounding factors. In addition, we identified that smoking status was also associated with lower GS values in contrast with previously published reports (18). Higher mean blood pressure has been previously independently associated with lower values of deformation (3). In contrast, hypertension and systolic blood pressures measured herein were mostly not significantly associated with GS (except GSepi with blood pressure, $\mathrm{p}=0.048$ ); these differences may be the consequence of the extensive adjustment used in the present study. Reduced GLS has been reported in dyslipidemic children and adolescents free of other cardiovascular risk factors or structural cardiac abnormalities 
compared with controls, with obesity causing an additive adverse effect on strain parameters (27).

Likewise, we identified a significant association of higher BMI with impaired GS values.

\section{Relationship between LV myocardial deformation and dyspnea symptom}

The prevalence of dyspnea increases with age with a peak incidence in patients aged 55 to 69 years (19), one half of whom will develop HFpEF (20). However, because the process of LV myocardial remodeling starts before the onset of symptoms, guidelines place special emphasis on the detection of subclinical functional and structural myocardial dysfunction and the timely identification of patients who are at risk of developing overt HF (21)(22). Pre-clinical diastolic dysfunction has been described in subjects without a diagnosis of congestive HF and with "normal" systolic function (LVEF) (23). According to the American College of Cardiology and American Heart Association (ACC/AHA) HF stages, patients at the lower end of the risk spectrum (stage A and B) are of particular interest and the most difficult to diagnose, since increases in LV filling pressures may only occur with exertion (24). Longitudinal strain was recently proven to provide incremental prognostic value beyond conventional measurements of LV structure and LVEF in identifying persons at risk for HF hospitalization or death (25). In stage A or B patients without signs or symptoms of overt HF but with potential structural heart disease or dyspnea, echocardiography represents a sensitive and practical tool to provide direct evaluation of myocardial function and left ventricular and atrial remodeling (26). However, the present is the first study to establish an association of a strain variable with clinical features (self-reported dyspnea). Self-reported dyspnea appears as an interesting outcome in this context as it is likely to be a symptom related to early-stage HFpEF. However, as participants did not undergo functional tests to identify the cause of dyspnea, we cannot ascertain that dyspnea was indeed related to early-stage HFpEF rather than other causes. Herein, we demonstrate longitudinal systolic dysfunction affecting only the subendocardium which would potentially allow targeted screening and the development of early diagnostic strategies in patients at risk for HFpEF (27)(28). In addition, we did not identify significant differences in classical diastolic Doppler parameters (including E/e') in participants with or 
without dyspnea: this could suggest that subtle systolic impairment could precede diastolic impairment in the genesis of HFpEF. Further studies are needed to assess the association between detailed strain measurements and the occurrence of HFpEF (29).

\section{RESEARCH AND CLINICAL IMPLICATIONS}

In this large cohort of subjects without cardiac disease (who could be considered as Stage A/B of the AHA heart failure classification), we were able to identify an association between layer-specific strain variables and self-reported dyspnea as opposed to other echocardiographic measurements which were not associated. This suggests that refined strain components (i.e. subendocardial strain) could help identify early stages of HFpEF, as demonstrated by an increased level of dyspnea. This novel finding necessitates further evaluation in future studies, particularly outcome-based studies, in order to determine whether impaired subendocardial strain is associated with a greater risk for mid/long-term overt HFpEF.

However, the absolute difference in GSendo\% was $0.5 \%$. This difference suggests that the isolated use of GSendo is not sufficiently discriminative in routine practice to incriminate myocardial dysfunction as the cause of dyspnea. However, GSendo\% was the only echocardiographic/deformation parameter to discriminate dyspnea and, as such, should probably be more systematically reported in current practice. In addition, these findings may pave the way for a multiparametric integrative approach of echocardiographic markers including GSendo\% among other variables in a near future. Constructing this rather complex algorithm would likely necessitate using machine learning approaches.

\section{LIMITATIONS}

Derived normal values were analyzed using a single type of ultrasound system and thus these values cannot be extrapolated to data obtained with systems from other manufacturers.(30) Some patients (8.2\%) had strain values obtained only from an apical 4-chamber image, although these can be useful when only limited images are obtained. 
Importantly, differences in subendocardial strain values and ratios, while statistically significant, are numerically quite small and may be difficult to translate into clinical significance. All subjects with known heart disease were excluded, such that the population that we attempted to phenotype (stage B patients with isolated dyspnea) is at the lower end of the risk spectrum.

In the STANISLAS cohort, the proportion of participants with dyslipidemia and hypertension was approximately $20 \%$. The proportion of participants with diabetes was $<5 \%$. The statistical power to detect and quantify the association of diabetes with strain parameters is consequently low.

\section{CONCLUSIONS}

This is the largest study to provide reference ranges for various indices of longitudinal deformation of the left ventricle during diastole and systole. We confirm the presence of a base-to-apex gradient and of a subendocardial to subepicardial gradient. This new echocardiographic approach using these validated normal ranges according to age and gender appears to be practical and ready for clinical use. Higher BMI was also found to be significantly associated with impaired strain in multivariable models in the present cohort without heart disease, thus suggesting that BMI is associated with subtle changes in strain at a very early stage of disease (Stage A/B of the AHA heart failure classification). Lastly, subjects with self-reported dyspnea, which is likely a symptom related to early-stage HFpEF, demonstrated a reduction in the subendocardial component of strain as well as transmural dispersion due to preferential involvement of the subendocardial fibers. While these strain variables need to be further investigated in outcome-based studies, our findings suggest that this specific strain component could be of value at very early stages of heart disease. 


\section{REFERENCES}

1. Mor-Avi V, Lang RM, Badano LP, Belohlavek M, Cardim NM, Derumeaux G, et al. Current and evolving echocardiographic techniques for the quantitative evaluation of cardiac mechanics: ASE/EAE consensus statement on methodology and indications endorsed by the Japanese Society of Echocardiography. J Am Soc Echocardiogr Off Publ Am Soc Echocardiogr. 2011 Mar;24(3):277-313.

2. Marwick TH, Leano RL, Brown J, Sun J-P, Hoffmann R, Lysyansky P, et al. Myocardial strain measurement with 2-dimensional speckle-tracking echocardiography: definition of normal range. JACC Cardiovasc Imaging. 2009 Jan;2(1):80-4.

3. Yingchoncharoen T, Agarwal S, Popović ZB, Marwick TH. Normal ranges of left ventricular strain: a meta-analysis. J Am Soc Echocardiogr Off Publ Am Soc Echocardiogr. 2013 Feb;26(2):185-91.

4. Farsalinos KE, Daraban AM, Ünlü S, Thomas JD, Badano LP, Voigt J-U. Head-to-Head Comparison of Global Longitudinal Strain Measurements among Nine Different Vendors: The EACVI/ASE Inter-Vendor Comparison Study. J Am Soc Echocardiogr Off Publ Am Soc Echocardiogr. 2015 Jul 23;

5. Voigt J-U, Pedrizzetti G, Lysyansky P, Marwick TH, Houle H, Baumann R, et al. Definitions for a common standard for 2D speckle tracking echocardiography: consensus document of the EACVI/ASE/Industry Task Force to standardize deformation imaging. $\mathbf{J}$ Am Soc Echocardiogr Off Publ Am Soc Echocardiogr. 2015 Feb;28(2):183-93.

6. Leitman M, Lysiansky M, Lysyansky P, Friedman Z, Tyomkin V, Fuchs T, et al. Circumferential and longitudinal strain in 3 myocardial layers in normal subjects and in patients with regional left ventricular dysfunction. J Am Soc Echocardiogr Off Publ Am Soc Echocardiogr. 2010 Jan;23(1):64-70.

7. Dyspnea. Mechanisms, assessment, and management: a consensus statement. American Thoracic Society. Am J Respir Crit Care Med. 1999 Jan;159(1):321-40.

8. Coiro S, Huttin O, Bozec E, Selton-Suty C, Lamiral Z, Carluccio E, et al. Reproducibility of echocardiographic assessment of 2D-derived longitudinal strain parameters in a population-based study (the STANISLAS Cohort study). Int J Cardiovasc Imaging. 2017 Mar 31;

9. Dalen H, Thorstensen A, Aase SA, Ingul CB, Torp H, Vatten LJ, et al. Segmental and global longitudinal strain and strain rate based on echocardiography of 1266 healthy individuals: the HUNT study in Norway. Eur J Echocardiogr J Work Group Echocardiogr Eur Soc Cardiol. 2010 Mar;11(2):176-83.

10. Dokainish H, Sengupta R, Pillai M, Bobek J, Lakkis N. Usefulness of new diastolic strain and strain rate indexes for the estimation of left ventricular filling pressure. Am J Cardiol. 2008 May 15;101(10):1504-9.

11. Kasner M, Gaub R, Sinning D, Westermann D, Steendijk P, Hoffmann W, et al. Global strain rate imaging for the estimation of diastolic function in HFNEF compared with pressure-volume loop analysis. Eur J Echocardiogr. 2010 Oct 1;11(9):743-51. 
12. Nagata Y, Wu VC-C, Otsuji Y, Takeuchi M. Normal range of myocardial layer-specific strain using two-dimensional speckle tracking echocardiography. PloS One. 2017;12(6):e0180584.

13. Sarvari SI, Haugaa KH, Zahid W, Bendz B, Aakhus S, Aaberge L, et al. Layer-specific quantification of myocardial deformation by strain echocardiography may reveal significant CAD in patients with non-ST-segment elevation acute coronary syndrome. JACC Cardiovasc Imaging. 2013 May;6(5):535-44.

14. Ozawa K, Funabashi N, Takaoka H, Kamata T, Kanaeda A, Saito M, et al. Characteristic myocardial strain identified in hypertrophic cardiomyopathy subjects with preserved left ventricular ejection fraction using a novel multi-layer transthoracic echocardiography technique. Int J Cardiol. 2015 Apr 1;184:237-43.

15. Sengupta SP, Caracciolo G, Thompson C, Abe H, Sengupta PP. Early impairment of left ventricular function in patients with systemic hypertension: new insights with 2dimensional speckle tracking echocardiography. Indian Heart J. 2013 Feb;65(1):48-52.

16. Zghal F, Bougteb H, Réant P, Lafitte S, Roudaut R. Assessing global and regional left ventricular myocardial function in elderly patients using the bidimensional strain method. Echocardiogr Mt Kisco N. 2011 Oct;28(9):978-82.

17. Cheng S, Larson MG, McCabe EL, Osypiuk E, Lehman BT, Stanchev P, et al. Age- and sex-based reference limits and clinical correlates of myocardial strain and synchrony: the Framingham Heart Study. Circ Cardiovasc Imaging. 2013 Sep;6(5):692-9.

18. Farsalinos K, Tsiapras D, Kyrzopoulos S, Voudris V. Acute and chronic effects of smoking on myocardial function in healthy heavy smokers: a study of Doppler flow, Doppler tissue velocity, and two-dimensional speckle tracking echocardiography. Echocardiogr Mt Kisco N. 2013 Mar;30(3):285-92.

19. Pesola GR, Ahsan H. Dyspnea as an independent predictor of mortality. Clin Respir J. 2016 Mar;10(2):142-52.

20. Zannad F, Adamopoulos C, Mebazaa A, Gheorghiade M. The challenge of acute decompensated heart failure. Heart Fail Rev. 2006 Jun;11(2):135-9.

21. Heart Failure Society Of America. Executive summary: HFSA 2006 Comprehensive Heart Failure Practice Guideline. J Card Fail. 2006 Feb;12(1):10-38.

22. Kane GC, Karon BL, Mahoney DW, Redfield MM, Roger VL, Burnett JC, et al. Progression of Left Ventricular Diastolic Dysfunction and Risk of Heart Failure. JAMA [Internet]. 2011 Aug 24 [cited 2014 Oct 18];306(8). Available from: http://apps.webofknowledge.com.gate2.inist.fr/CitedFullRecord.do?product=WOS\&colNa me $=$ WOS \&SID=W25F7OeKNreI7rkki3F\&search_mode=CitedFullRecord\&isickref=WO S:000294157300023\&cacheurlFromRightClick=no

23. Wan S-H, Vogel MW, Chen HH. Pre-Clinical Diastolic Dysfunction. J Am Coll Cardiol. 2014 Feb 11;63(5):407-16.

24. Jessup M, Abraham WT, Casey DE, Feldman AM, Francis GS, Ganiats TG, et al. 2009 focused update: ACCF/AHA Guidelines for the Diagnosis and Management of Heart 
Failure in Adults: a report of the American College of Cardiology Foundation/American Heart Association Task Force on Practice Guidelines: developed in collaboration with the International Society for Heart and Lung Transplantation. Circulation. 2009 Apr 14;119(14):1977-2016.

25. Yang H, Negishi K, Wang Y, Nolan M, Saito M, Marwick TH. Echocardiographic screening for non-ischaemic stage B heart failure in the community. Eur J Heart Fail. 2016 Nov;18(11):1331-9.

26. Nagueh SF, Appleton CP, Gillebert TC, Marino PN, Oh JK, Smiseth OA, et al. Recommendations for the evaluation of left ventricular diastolic function by echocardiography. Eur J Echocardiogr J Work Group Echocardiogr Eur Soc Cardiol. 2009 Mar;10(2):165-93.

27. Edelmann F, Wachter R, Schmidt AG, Kraigher-Krainer E, Colantonio C, Kamke W, et al. Effect of spironolactone on diastolic function and exercise capacity in patients with heart failure with preserved ejection fraction: the Aldo-DHF randomized controlled trial. JAMA. 2013 Feb 27;309(8):781-91.

28. Solomon SD, Verma A, Desai A, Hassanein A, Izzo J, Oparil S, et al. Effect of intensive versus standard blood pressure lowering on diastolic function in patients with uncontrolled hypertension and diastolic dysfunction. Hypertension. 2010 Feb;55(2):2418 .

29. Shah AM, Claggett B, Loehr LR, Chang PP, Matsushita K, Kitzman D, et al. Heart Failure Stages Among Older Adults in the Community: The Atherosclerosis Risk in Communities Study. Circulation. 2016 Nov 23;

30. Shah AM, Solomon SD. Myocardial deformation imaging: current status and future directions. Circulation. 2012 Jan 17;125(2):e244-8. 


\section{ACKNOWLEDGEMENTS}

Subjects were included in the STANISLAS COHORT which was supported by grants from the French Ministry of Health (Programme Hospitalier de Recherche Clinique Inter-régional 2008 - 2013) and sponsored by the CHU Nancy, F-54000, Nancy, France.

The authors deeply thank the entire Clinical Investigation Centre staff all of whom are involved in the daily management of the STANISLAS cohort. We also thank Mr. Pierre Pothier for the editing of the manuscript.

SOURCES OF FUNDING: The STANISLAS study was sponsored by Nancy CHRU and supported by a public grant overseen by the French National Research Agency (ANR) as part of the second "Investissements d'Avenir" programme (reference: ANR-15-RHUS-0004).

\section{FIGURES}

FIGURE 1: Longitudinal deformation (transmural and layer-specific) curves measured by speckle tracking echocardiography. (L: longest length during systole; L0: longest length at the end of diastole; ESS: end systolic strain; $\mathrm{p}^{\circ} \mathrm{SS}$ : Post systolic strain; EPS: early positive systolic peak strain).

FIGURE 2: Longitudinal strain curves measured by speckle tracking echocardiography with deformation pattern of a segment with transmural strain, layer specific strain (subepicardial and endocardial) and systolic diastolic strain rate.

FIGURE 3: Segmental distribution of 19591 myocardial segments for global multilayer longitudinal and temporal longitudinal strain values. Early systolic lengthening of the segment ( $\left.{ }^{\circ} \mathrm{PST}\right)$, post systolic shortening and peak strain $\left(\mathrm{P}^{\circ} \mathrm{SI}\right)$, global strain (GS). 


\begin{tabular}{|c|c|c|c|c|c|c|c|c|c|}
\hline & $\begin{array}{l}\text { Entire popula } \\
(\mathrm{N}=1243)\end{array}$ & ation & $\begin{array}{l}\text { Age 20-40 years } \\
(\mathrm{N}=503)\end{array}$ & $\begin{array}{l}\text { Age 40-60 years } \\
(\mathrm{N}=399)\end{array}$ & $\begin{array}{l}\text { Age }>60 \text { years } \\
(\mathrm{N}=339)\end{array}$ & & $\begin{array}{l}\text { Men } \\
(\mathrm{N}=\mathbf{5 9 0}) \\
\end{array}$ & $\begin{array}{l}\text { Women } \\
(\mathrm{N}=653) \\
\end{array}$ & \\
\hline Characteristic & Mean+SD & median (Q1-Q3) & $\begin{array}{l}\text { Mean+SD/ } \\
\text { median (Q1-Q3) }\end{array}$ & $\begin{array}{l}\text { Mean+SD/ } \\
\text { median (Q1-Q3) }\end{array}$ & $\begin{array}{l}\text { Mean+SD/ } \\
\text { median (Q1-Q3) }\end{array}$ & P-value & $\begin{array}{l}\text { Mean+SD/ } \\
\text { median }(\mathrm{Q} 1-\mathrm{Q} 3)\end{array}$ & $\begin{array}{l}\text { Mean+SD/ } \\
\text { median }(\mathrm{Q} 1-\mathrm{Q} 3)\end{array}$ & P-value \\
\hline Age (years, mean $\pm \mathrm{SD}$ ) & $48 \pm 14$ & $54(34-60)$ & $33(30-36)$ & $56(53-58)$ & $63(61-65)$ & $<0.0001$ & $56(34-61)$ & $53(34-59)$ & 0.001 \\
\hline Height $(\mathrm{m}$, mean $\pm \mathrm{SD})$ & $1.69 \pm 0.09$ & $1.69(1.62-1.76)$ & $1.71 \pm 0.09$ & $1.67 \pm 0.09$ & $1.67 \pm 0.09$ & $<0.0001$ & $1.75 \pm 0.07$ & $1.63 \pm 0.07$ & $<0.0001$ \\
\hline Weight $(\mathrm{Kg}$, mean $\pm \mathrm{SD})$ & $73 \pm 14$ & $72(62-81)$ & $70(60-81)$ & $71(62-81)$ & $74(64-84)$ & 0.02 & $78(72-87)$ & $63(57-72)$ & $<0.0001$ \\
\hline $\mathrm{BMI}\left(\mathrm{Kg} / \mathrm{m}^{2}\right.$, mean $\left.\pm \mathrm{SD}\right)$ & $25 \pm 4$ & $25(22-28)$ & $24(21-26)$ & $25(23-28)$ & $26(24-28)$ & $<0.0001$ & $25(23-28)$ & $24(22-27)$ & $<0.0001$ \\
\hline $\mathrm{WC}(\mathrm{cm})$ & $\begin{array}{l}88.33 \pm \\
12.33\end{array}$ & $\begin{array}{l}88.00(79.00- \\
97.00)\end{array}$ & $84.35 \pm 11.92$ & $89.77 \pm 11.91$ & $92.57 \pm 11.69$ & $<0.0001$ & $93.53 \pm 10.48$ & $83.62 \pm 12.00$ & $<0.0001$ \\
\hline Systolic blood pressure, $\mathrm{mmHg}$ & $125 \pm 15$ & $123(113-134)$ & $118(110-127)$ & $124(115-134)$ & $130(119-141)$ & $<0.0001$ & $128(120-137)$ & $117(110-128)$ & $<0.0001$ \\
\hline Diastolic blood pressure, $\mathrm{mmHg}$ & $72 \pm 9$ & $71(66-77)$ & $69 \pm 8$ & $74 \pm 9$ & $74 \pm 9$ & $<0.0001$ & $75 \pm 8$ & $69 \pm 8$ & $<0.0001$ \\
\hline Heart rate (bpm) & $64 \pm 9$ & $63(57-69)$ & $64 \pm 9$ & $63 \pm 8$ & $64 \pm 9$ & 0.21 & $62 \pm 9$ & $65 \pm 9$ & $<0.0001$ \\
\hline Total Cholesterol level, g/L & $2.13 \pm 0.39$ & $2.10(1.86-2.40)$ & $1.96 \pm 0.35$ & $2.26 \pm 0.37$ & $2.24 \pm 0.38$ & $<0.0001$ & $2.09 \pm 0.39$ & $2.17 \pm 0.40$ & 0.0008 \\
\hline HDL Cholesterol level, g/L & $0.58 \pm 0.14$ & $0.57(0.48-0.67)$ & $0.54(0.46-0.63)$ & $0.59(0.50-0.69)$ & $0.59(0.50-0.68)$ & $<0.0001$ & $0.52(0.44-0.61)$ & $0.62(0.53-0.71)$ & $<0.0001$ \\
\hline LDL Cholesterol level, g/L & $1.35 \pm 0.34$ & $1.32(1.12-1.56)$ & $1.23 \pm 0.31$ & $1.44 \pm 0.33$ & $1.42 \pm 0.34$ & $<0.0001$ & $1.34 \pm 0.34$ & $1.35 \pm 0.34$ & 0.51 \\
\hline Triglyceride level, g/L & $1.02 \pm 0.53$ & $0.89(0.65-1.22)$ & $0.78(0.59-1.09)$ & $0.92(0.67-1.29)$ & $1.01(0.77-1.30)$ & $<0.0001$ & $0.95(0.69-1.33)$ & $0.85(0.63-1.12)$ & $<0.0001$ \\
\hline Blood glucose, (g/L) & $0.90 \pm 0.16$ & $0.88(0.82-0.94)$ & $0.84(0.78-0.89)$ & $0.89(0.85-0.95)$ & $0.92(0.86-1.00)$ & $<0.0001$ & $0.90(0.84-0.97)$ & $0.86(0.81-0.92)$ & $<0.0001$ \\
\hline $\begin{array}{l}\text { eGFR (MDRD formula) } \\
(\mathrm{mL} / \mathrm{min} / 1.73 \mathrm{~m} 2)\end{array}$ & $\begin{array}{l}96.13 \pm \\
17.24\end{array}$ & $\begin{array}{l}95.25(84.20- \\
106.10)\end{array}$ & $103.31 \pm 15.19$ & $92.94 \pm 15.99$ & $89.22 \pm 17.62$ & $<0.0001$ & $97.39 \pm 17.43$ & $94.98 \pm 16.99$ & 0.014 \\
\hline & \multicolumn{2}{|l|}{ n (\%) } & n (\%) & n (\%) & n (\%) & P-value & n (\%) & n (\%) & P-value \\
\hline Female gender & \multicolumn{2}{|l|}{$653(52.5 \%)$} & $274(54 \%)$ & $235(59 \%)$ & $143(42 \%)$ & $<0.0001$ & & & \\
\hline Current smoker & \multicolumn{2}{|l|}{$289(23.3 \%)$} & $177(35 \%)$ & $72(18 \%)$ & $40(12 \%)$ & $<0.0001$ & $147(25 \%)$ & $142(22 \%)$ & 0.19 \\
\hline Overweight $(\mathrm{BMI}>25)$ & \multicolumn{2}{|l|}{$596(47.9 \%)$} & $179(36 \%)$ & $215(54 \%)$ & $202(60 \%)$ & $<0.0001$ & $331(56 \%)$ & $265(41 \%)$ & $<0.0001$ \\
\hline Diabetes Mellitus & \multicolumn{2}{|l|}{$36(2.9 \%)$} & $6(1 \%)$ & $5(1 \%)$ & $25(7 \%)$ & $<0.0001$ & $21(4 \%)$ & $15(2 \%)$ & 0.19 \\
\hline HBP self-reported by patient & \multicolumn{2}{|l|}{$203(16.3 \%)$} & $15(3 \%)$ & $82(21 \%)$ & $106(31 \%)$ & $<0.0001$ & $98(17 \%)$ & $105(16 \%)$ & 0.81 \\
\hline Dyslipidemia & \multicolumn{2}{|l|}{$268(21.6 \%)$} & $47(9 \%)$ & $90(23 \%)$ & $131(39 \%)$ & $<0.0001$ & $136(23 \%)$ & $132(20 \%)$ & 0.23 \\
\hline $\mathrm{ARB}$ & \multicolumn{2}{|l|}{$81(6.5 \%)$} & $3(1 \%)$ & $32(8 \%)$ & $46(14 \%)$ & $<0.0001$ & $53(9 \%)$ & $28(4 \%)$ & 0.0008 \\
\hline Beta blockers & \multicolumn{2}{|l|}{$70(5.6 \%)$} & $4(1 \%)$ & $30(8 \%)$ & $36(11 \%)$ & $<0.0001$ & $32(5 \%)$ & $38(6 \%)$ & 0.76 \\
\hline Diuretics (thiazide) & \multicolumn{2}{|l|}{$57(4.6 \%)$} & $3(1 \%)$ & $21(5 \%)$ & $33(10 \%)$ & $<0.0001$ & $29(5 \%)$ & $28(4 \%)$ & 0.6 \\
\hline ACE & \multicolumn{2}{|l|}{$36(2.9 \%)$} & $1(0 \%)$ & $12(3 \%)$ & $23(7 \%)$ & $<0.0001$ & $21(4 \%)$ & $15(2 \%)$ & 0.19 \\
\hline
\end{tabular}

HBP : High blood pressure ACE : angiotensin-converting enzyme; ARB : angiotensin ii receptor antagonist; eGFR estimated Glomerular Filtration Rate: BMI : Body Mass index ; WC Waist circumference 


\begin{tabular}{|c|c|c|c|c|c|c|c|c|}
\hline & & & Before weighting & & & After weighting* & & \\
\hline & \multicolumn{2}{|c|}{$\begin{array}{l}\text { Entire population } \\
\text { Total }(N=1243)\end{array}$} & \multirow{2}{*}{$\begin{array}{l}\text { Dyspnea No } \\
(\mathrm{N}=1052) \\
\begin{array}{l}\text { Mean } \pm \mathrm{SD} / \\
\text { median}(\mathrm{Q} 1-\mathrm{Q})\end{array}\end{array}$} & \multicolumn{2}{|l|}{$\begin{array}{l}\text { Dyspnea Yes } \\
(\mathrm{N}=170)\end{array}$} & \multirow{2}{*}{$\begin{array}{l}\text { Dyspnea No } \\
(\mathrm{N}=1052) \\
\begin{array}{l}\text { Mean } \pm \text { SD/ } \\
\text { median(Q1-Q3) }\end{array}\end{array}$} & \multirow{2}{*}{$\begin{array}{l}\text { Dyspnea Yes } \\
(\mathrm{N}=170) \\
\begin{array}{l}\text { Mean } \pm \mathrm{SD} / \\
\text { median(Q1-Q3) }\end{array}\end{array}$} & \multirow[b]{2}{*}{ P-valuc } \\
\hline & Mean+SD & Median(Q1-Q3) & & $\begin{array}{l}\text { Mean } \pm \text { SD } \\
/ \text { median }(Q 1-Q 3)\end{array}$ & P-value & & & \\
\hline $\begin{array}{l}\text { Septal wall thickness (SWT) (mm) } \\
\text { 2D }\end{array}$ & $9.35 \pm 1.65$ & $9.30(8.20-10.40)$ & $9.33 \pm 1.63$ & $9.41 \pm 1.73$ & 0.54 & $9.35 \pm 1.63$ & $9.24 \pm 1.80$ & 0.44 \\
\hline $\mathrm{LV}$ mass index ASE $\left(\mathrm{g} / \mathrm{m}^{2}\right) 2 \mathrm{D}$ & $74.59 \pm 17.83$ & $72.70(61.98-84.52)$ & $\begin{array}{l}72.76(62.35- \\
84.72)\end{array}$ & $\begin{array}{l}70.53(59.96- \\
83.45)\end{array}$ & 0.20 & $72.76(62.62-84.83)$ & $70.69(60.13-83.43)$ & 0.59 \\
\hline $\operatorname{LVEF}(\%)$ & $65.13 \pm 6.50$ & $65.26(61.27-69.28)$ & $65.16 \pm 6.55$ & $65.19 \pm 6.31$ & 0.96 & $65.28 \pm 6.53$ & $64.30 \pm 6.37$ & 0.078 \\
\hline LV End-diastolic volume $\left(\mathrm{ml} / \mathrm{m}^{2}\right)$ & $49.92 \pm 12.47$ & $49.10(41.14-57.43)$ & $50.22 \pm 12.51$ & $48.02 \pm 11.36$ & 0.037 & $49.79 \pm 12.46$ & $50.27 \pm 10.61$ & 0.65 \\
\hline LV End-systolic volume (ml/m²) & $17.62 \pm 6.08$ & $16.71(13.41-20.89)$ & $\begin{array}{l}16.71(13.55- \\
21.06)\end{array}$ & $\begin{array}{l}16.32(12.70- \\
19.61)\end{array}$ & 0.17 & $16.51(13.30-20.84)$ & $17.82(14.47-20.79)$ & 0.22 \\
\hline Left atrial volume index $\left(\mathrm{ml} / \mathrm{m}^{2}\right)$ & $22.29 \pm 6.87$ & $21.53(17.56-26.20)$ & $\begin{array}{l}21.56(17.53- \\
26.25)\end{array}$ & $\begin{array}{l}21.44(18.26- \\
25.59)\end{array}$ & 0.93 & $21.63(17.50-26.26)$ & $21.37(18.06-24.46)$ & 0.45 \\
\hline $\mathrm{E} / \mathrm{A}$ ratio & $1.22 \pm 0.43$ & $1.15(0.89-1.48)$ & $1.16(0.91-1.49)$ & $1.01(0.85-1.30)$ & 0.0004 & $1.15(0.89-1.47)$ & $1.17(0.91-1.54)$ & 0.53 \\
\hline $\begin{array}{l}\text { E wave Deceleration time (DT) } \\
\text { (ms) }\end{array}$ & $\begin{array}{l}210.28 \pm \\
52.52\end{array}$ & $\begin{array}{l}206.26(173.53- \\
240.53)\end{array}$ & $210.16 \pm 52.77$ & $213.51 \pm 52.29$ & 0.46 & $210.55 \pm 52.83$ & $212.39 \pm 51.44$ & 0.68 \\
\hline $\mathrm{E} / \mathrm{e}^{\prime}$ & $6.29 \pm 1.69$ & $6.06(5.11-7.17)$ & $5.98(5.05-7.11)$ & $6.42(5.49-7.51)$ & 0.002 & $6.07(5.12-7.17)$ & $6.00(5.01-7.12)$ & 0.85 \\
\hline S/D PVF & $1.33 \pm 0.36$ & $1.29(1.09-1.56)$ & $1.28(1.08-1.55)$ & $1.39(1.20-1.66)$ & 0.0009 & $1.30(1.09-1.57)$ & $1.32(1.14-1.59)$ & 0.40 \\
\hline $\mathrm{S}^{\prime}(\mathrm{cm} / \mathrm{s})$ & $8.69 \pm 1.78$ & $8.54(7.46-9.65)$ & $8.75 \pm 1.78$ & $8.24 \pm 1.65$ & 0.002 & $8.70 \pm 1.77$ & $8.55 \pm 1.92$ & 0.33 \\
\hline A reverse - A diastole (ms) & $\begin{array}{l}-26.48 \pm \\
31.82\end{array}$ & $\begin{array}{l}-25.37(-42.38-- \\
7.78)\end{array}$ & $\begin{array}{l}-25.37(-42.38-- \\
7.92)\end{array}$ & $\begin{array}{l}-25.40(-43.71-- \\
8.95)\end{array}$ & 0.81 & $-25.38(-42.38--8.31)$ & $-23.07(-43.59--10.78)$ & 0.28 \\
\hline $\mathrm{E} / \mathrm{Vp}$ & $1.34 \pm 0.55$ & $1.31(0.97-1.65)$ & $1.32(0.97-1.66)$ & $1.23(0.93-1.61)$ & 0.10 & $1.31(0.97-1.66)$ & $1.27(0.99-1.65)$ & 0.52 \\
\hline IVRT (ms) & $81.68 \pm 19.29$ & $80.74(68.33-94.25)$ & $81.60 \pm 19.21$ & $82.16 \pm 19.38$ & 0.73 & $82.00 \pm 19.21$ & $78.45 \pm 20.24$ & 0.033 \\
\hline $\begin{array}{l}\text { Tricuspid regurgitant velocity } \\
(\mathrm{m} / \mathrm{s})\end{array}$ & $2.13 \pm 0.32$ & $2.13(1.96-2.34)$ & $2.13(1.97-2.34)$ & $2.13(1.90-2.32)$ & 0.32 & $2.14(1.98-2.36)$ & $2.03(1.80-2.24)$ & 0.01 \\
\hline
\end{tabular}


Table 3: Multivariable model with strain values as outcome

\begin{tabular}{|c|c|c|c|c|c|c|c|c|c|c|c|c|c|c|c|c|c|}
\hline & \multirow{2}{*}{\multicolumn{2}{|c|}{$\begin{array}{c}\text { GSendo (\%) } \\
\mathbf{R}^{2}=12.8 \%\end{array}$}} & \multirow{2}{*}{\multicolumn{2}{|c|}{$\begin{array}{c}\text { GS Full-wall (\%) } \\
\qquad \mathbf{R}^{2}=12.5 \%\end{array}$}} & \multirow{2}{*}{\multicolumn{2}{|c|}{$\begin{array}{l}\text { GS epi (\%) } \\
R^{2}=11.0 \%\end{array}$}} & \multirow{2}{*}{\multicolumn{2}{|c|}{$\begin{array}{c}\text { GSRs } \\
R^{2}=6.8 \%\end{array}$}} & \multirow{2}{*}{\multicolumn{2}{|c|}{$\begin{array}{c}\text { GSRe } \\
\mathbf{R}^{2}=39.4 \%\end{array}$}} & \multirow{2}{*}{\multicolumn{2}{|c|}{$\begin{array}{c}\text { GSRa } \\
\mathbf{R}^{2}=37.7 \%\end{array}$}} & \multirow{2}{*}{\multicolumn{3}{|c|}{$\begin{array}{c}\text { EPS } \\
R^{2}=6.1 \%\end{array}$}} & \multirow{2}{*}{\multicolumn{2}{|c|}{$\begin{array}{c}\mathrm{P}^{\circ} \mathrm{SS} \\
\mathrm{R}^{2}=13.1 \%\end{array}$}} \\
\hline & & & & & & & & & & & & & & & & & \\
\hline & $\boldsymbol{\beta} \pm \mathbf{S E}$ & P-value & $\boldsymbol{\beta} \pm \mathbf{S E}$ & P-value & $\boldsymbol{\beta} \pm \mathbf{S E}$ & $\begin{array}{l}\text { P- } \\
\text { value }\end{array}$ & $\boldsymbol{\beta} \pm \mathbf{S E}$ & P-value & $\boldsymbol{\beta} \pm \mathbf{S E}$ & $\begin{array}{l}\text { P- } \\
\text { value }\end{array}$ & $\boldsymbol{\beta} \pm \mathbf{S E}$ & $\begin{array}{l}P \text { - } \\
\text { value }\end{array}$ & $\boldsymbol{\beta} \pm \mathbf{S E}$ & $\begin{array}{l}\text { P- } \\
\text { val }\end{array}$ & & $\boldsymbol{\beta} \pm \mathbf{S E}$ & P-value \\
\hline Intercept & $\begin{array}{l}-27.86 \pm \\
0.96\end{array}$ & $<0.0001$ & $\begin{array}{l}-25.47 \pm \\
0.88\end{array}$ & $<.0001$ & $\begin{array}{l}-23.25 \pm \\
0.87\end{array}$ & $<.0001$ & $-1.09 \pm 0.06$ & $<.0001$ & $2.75 \pm 0.11$ & $<.0001$ & $\begin{array}{ll}1 & -0.13 \pm 0.07\end{array}$ & $7 \quad 0.070$ & $0.20 \pm 0.1$ & & 0.14 & $\begin{array}{l}-26.22 \pm \\
0.87\end{array}$ & $<.0001$ \\
\hline $\begin{array}{l}\text { Age (per } 10 \text { yr } \\
\text { increment) }\end{array}$ & $-0.03 \pm 0.01$ & $<0.0001$ & $-0.03 \pm 0.01$ & $<.0001$ & $-0.02 \pm 0.01$ & 0.0001 & $\begin{array}{l}-0.001 \pm \\
0.0004\end{array}$ & 0.001 & $\begin{array}{l}-0.01 \pm \\
0.0007\end{array}$ & $<.0001$ & $\begin{array}{ll}1 & 0.01 \pm \\
& 0.0005\end{array}$ & $<.0001$ & $1 \begin{array}{l}0.0006 \pm \\
0.001\end{array}$ & & 0.52 & $-0.03 \pm 0.01$ & $1<.0001$ \\
\hline Female & $-1.34 \pm 0.17$ & $<0.0001$ & $-1.23 \pm 0.16$ & $<.0001$ & $-1.13 \pm 0.15$ & $<.0001$ & $0.01 \pm 0.01$ & 0.17 & $0.19 \pm 0.02$ & $<.0001$ & $\begin{array}{ll}1 & -0.01 \pm 0.01\end{array}$ & 0.61 & $0.18 \pm 0.0$ & & $\begin{array}{l}<.000 \\
1\end{array}$ & $\begin{array}{ll}0 & -1.25 \pm 0.15\end{array}$ & $5<.0001$ \\
\hline $\begin{array}{l}\text { Current } \\
\text { smoker }\end{array}$ & $0.38 \pm 0.19$ & 0.043 & $0.36 \pm 0.18$ & 0.039 & $0.34 \pm 0.17$ & 0.048 & $0.03 \pm 0.01$ & 0.014 & $-0.01 \pm 0.02$ & $2 \quad 0.77$ & $-0.04 \pm 0.01$ & 0.008 & $0.01 \pm 0.0$ & & 0.85 & $0.37 \pm 0.17$ & 0.033 \\
\hline Diabetes & $-0.43 \pm 0.48$ & 0.36 & $-0.22 \pm 0.44$ & 0.61 & $-0.05 \pm 0.43$ & 0.92 & $0.01 \pm 0.03$ & 0.75 & $0.12 \pm 0.06$ & 0.031 & $-0.04 \pm 0.04$ & 0.28 & $-0.13 \pm 0$. & & 0.042 & $2 \quad-0.15 \pm 0.43$ & $\begin{array}{ll}3 & 0.73\end{array}$ \\
\hline $\begin{array}{l}\text { BMI (per } 1 \\
\mathrm{~kg} / \mathrm{m}^{2} \\
\text { increment) }\end{array}$ & $0.11 \pm 0.02$ & $<0.0001$ & $0.10 \pm 0.02$ & $<.0001$ & $0.08 \pm 0.02$ & $<.0001$ & $0.01 \pm 0.00$ & $<.0001$ & $\begin{array}{l}-0.01 \pm \\
0.002\end{array}$ & $<.0001$ & $\begin{array}{ll}1 & 0.003 \pm \\
0.001\end{array}$ & 0.041 & $-0.01 \pm 0$ & & 0.012 & $2 \quad 0.10 \pm 0.02$ & $<.0001$ \\
\hline HBP & $-0.03 \pm 0.24$ & 0.89 & $-0.05 \pm 0.22$ & 0.82 & $-0.07 \pm 0.21$ & 0.75 & $-0.02 \pm 0.02$ & 0.21 & $-0.03 \pm 0.03$ & 30.36 & $0.01 \pm 0.02$ & 0.44 & $-0.06 \pm 0$. & & 0.053 & $3-0.11 \pm 0.21$ & $1 \quad 0.61$ \\
\hline Dysplipidemia & $0.22 \pm 0.20$ & 0.27 & $0.18 \pm 0.18$ & 0.33 & $0.15 \pm 0.18$ & 0.41 & $\begin{array}{l}-0.003 \pm \\
0.01\end{array}$ & 0.79 & $-0.01 \pm 0.02$ & $2 \quad 0.68$ & $0.001 \pm 0.01$ & $1 \quad 0.92$ & $0.05 \pm 0.0$ & & 0.085 & $5 \quad 0.17 \pm 0.18$ & 0.35 \\
\hline Dyspnea & $0.54 \pm 0.23$ & 0.019 & $0.39 \pm 0.21$ & 0.068 & $0.26 \pm 0.21$ & 0.21 & $0.03 \pm 0.01$ & 0.044 & $-0.01 \pm 0.03$ & $3 \quad 0.79$ & $-0.03 \pm 0.02$ & 0.13 & $0.06 \pm 0.0$ & & 0.066 & $\begin{array}{ll}6 & 0.33 \pm 0.21\end{array}$ & 0.11 \\
\hline $\begin{array}{l}\text { SBM (per } 10 \\
\text { mmHg } \\
\text { increment) }\end{array}$ & $0.04 \pm 0.06$ & 0.51 & $0.08 \pm 0.06$ & 0.17 & $0.11 \pm 0.06$ & 0.048 & $0.01 \pm 0.003$ & $\begin{array}{ll}3 & 0.049\end{array}$ & $-0.03 \pm 0.01$ & 0.0003 & $3 \quad 0.01 \pm 0.00$ & 0.066 & $0.03 \pm 0.0$ & & 0.003 & $\begin{array}{ll}3 & 0.10 \pm 0.06\end{array}$ & 0.094 \\
\hline Heart rate & $0.46 \pm 0.09$ & $<0.0001$ & $0.39 \pm 0.08$ & $\begin{array}{l}<0.000 \\
1\end{array}$ & $0.33 \pm 0.08$ & $<.0001$ & $-0.04 \pm 0.01$ & $<.0001$ & $-0.03 \pm 0.01$ & 0.004 & $0.06 \pm 0.01$ & $<.0001$ & $\begin{array}{ll}1 & -0.005 \pm \\
0.01\end{array}$ & & 0.70 & $0.35 \pm 0.08$ & $<.0001$ \\
\hline LVH & $0.80 \pm 0.24$ & 0.001 & $0.69 \pm 0.23$ & 0.002 & $0.60 \pm 0.22$ & 0.006 & $0.04 \pm 0.02$ & 0.014 & $-0.04 \pm 0.03$ & 0.21 & $-0.01 \pm 0.02$ & 0.43 & $\begin{array}{l}-0.003 \pm \\
0.03\end{array}$ & & 0.92 & $0.40 \pm 0.22$ & 0.069 \\
\hline
\end{tabular}


GSendo, Global subendocardial peak longitudinal strain; GSfull-wall, Global full-wall peak longitudinal strain; GSepi, Global subendocardial peak longitudinal strain; GSRs 1/sec, Global systolic peak longitudinal strain rate; GSRe 1/sec, Global early diastolic peak longitudinal strain rate; GSRa 1/sec, Global late diastolic peak longitudinal strain rate; $P^{\circ}$ SS, post systolic strain; EPS, early systolic pre-stretch strain; $P^{\circ}$ SI, full-wall post-systolic index; ${ }^{\circ} P S T$, full-wall pre-stretch index;

Table 4: Left ventricular deformation parameters according to dyspnea status

\begin{tabular}{|c|c|c|c|c|c|c|}
\hline \multirow[b]{2}{*}{ 2D Deformation value } & \multicolumn{3}{|l|}{ Before weighting } & \multicolumn{3}{|l|}{ After weighting } \\
\hline & Dyspnea No & Dyspnea Yes & & Dyspnea No & Dyspnea Yes & \\
\hline & $(\mathrm{N}=1052)$ & $(\mathrm{N}=170)$ & & $(\mathrm{N}=1052)$ & $(\mathrm{N}=170)$ & \\
\hline & $\begin{array}{l}\text { Mean } \pm \text { SD/ } \\
\text { median(Q1-Q3) }\end{array}$ & $\begin{array}{l}\text { Mean } \pm \mathrm{SD} \\
/ \text { median(Q1-Q3) }\end{array}$ & P-value & $\begin{array}{l}\text { Mean } \pm \text { SD/ } \\
\text { median(Q1-Q3) }\end{array}$ & $\begin{array}{l}\text { Mean } \pm \text { SD/ } \\
\text { median(Q1-Q3) }\end{array}$ & P-value \\
\hline GSendo \% & $-23.48 \pm 2.69$ & $-23.07 \pm 2.90$ & 0.066 & $-23.48 \pm 2.70$ & $-23.02 \pm 2.81$ & 0.043 \\
\hline GSfull-wall \% & $-21.16 \pm 2.49$ & $-20.88 \pm 2.78$ & 0.17 & $-21.16 \pm 2.50$ & $-20.87 \pm 2.67$ & 0.16 \\
\hline GSepi \% & $-19.16 \pm 2.43$ & $-18.99 \pm 2.72$ & 0.41 & $-19.15 \pm 2.44$ & $-18.99 \pm 2.60$ & 0.42 \\
\hline GSendo/ GSepi ratio & $1.21(1.18-1.27)$ & $1.20(1.18-1.25)$ & 0.17 & $1.21(1.18-1.27)$ & $1.20(1.18-1.24)$ & 0.034 \\
\hline GSendo Base-apex ratio & $0.65(0.58-0.72)$ & $0.64(0.56-0.72)$ & 0.24 & $0.65(0.58-0.72)$ & $0.65(0.57-0.72)$ & 0.45 \\
\hline GSfull-wall Base- apex ratio & $0.79(0.71-0.87)$ & $0.78(0.67-0.87)$ & 0.26 & $0.79(0.70-0.87)$ & $0.78(0.68-0.87)$ & 0.24 \\
\hline GSepi Base-apex ratio & $0.93(0.83-1.05)$ & $0.92(0.80-1.03)$ & 0.15 & $0.93(0.82-1.05)$ & $0.92(0.80-1.01)$ & 0.16 \\
\hline GSRs 1/sec & $-1.13(-1.23--1.00)$ & $-1.08(-1.20--0.97)$ & 0.044 & $-1.13(-1.23--1.00)$ & $-1.10(-1.23--1.00)$ & 0.31 \\
\hline GSRe 1/sec & $1.37(1.10-1.63)$ & $1.23(1.07-1.57)$ & 0.013 & $1.33(1.07-1.63)$ & $1.33(1.10-1.70)$ & 0.93 \\
\hline GSRa 1/sec & $0.83(0.67-1.03)$ & $0.90(0.73-1.07)$ & 0.026 & $0.87(0.67-1.03)$ & $0.80(0.67-1.00)$ & 0.1 \\
\hline
\end{tabular}

GSendo, Global subendocardial peak longitudinal strain; GSfull-wall, Global full-wall peak longitudinal strain; GSepi, Global subendocardial peak longitudinal strain; GSRs 1/sec, Global systolic peak longitudinal strain rate; GSRe 1/sec, Global early diastolic peak longitudinal strain rate; GSRa 1/sec, Global late diastolic peak longitudinal strain rate; 


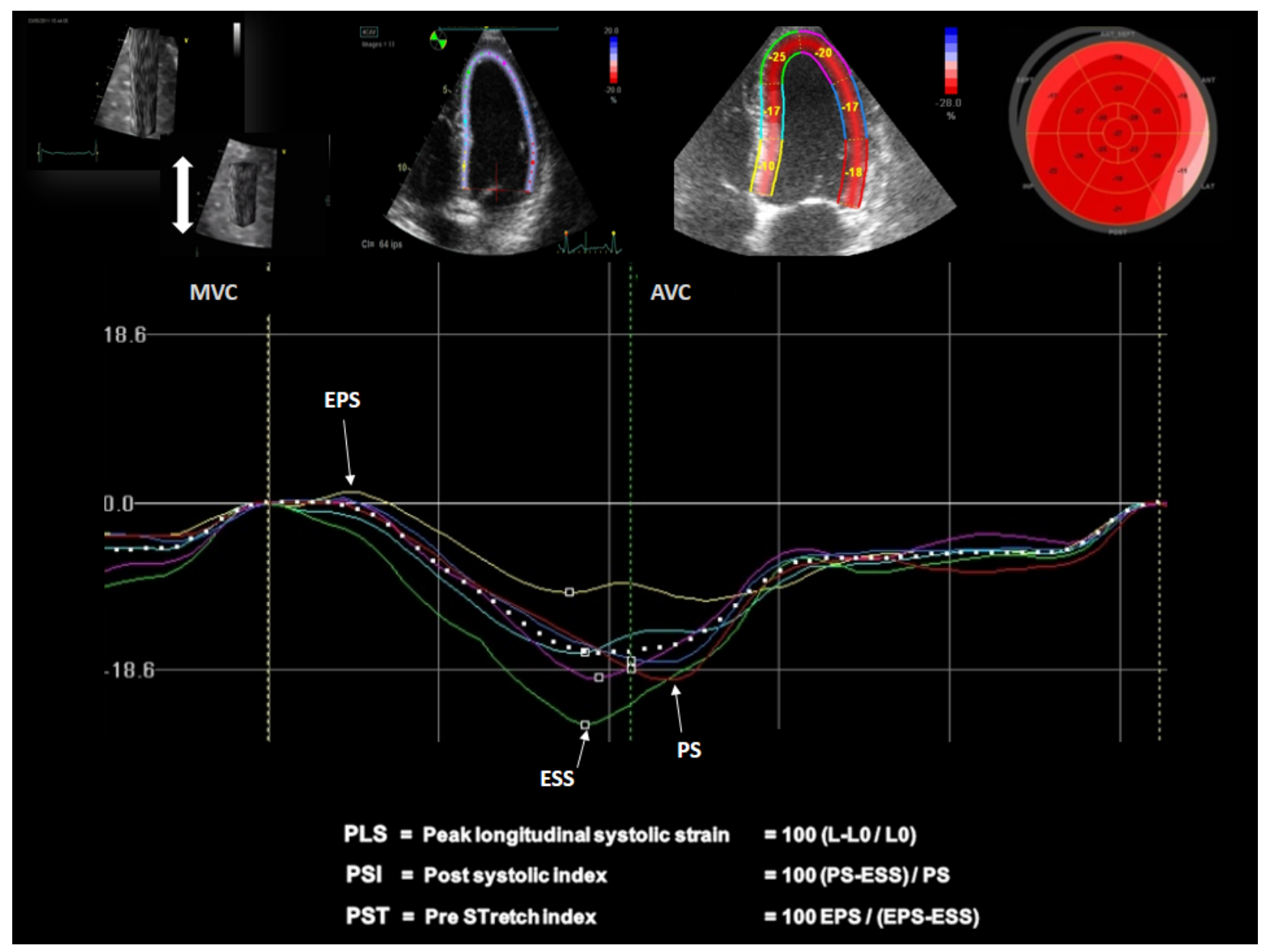



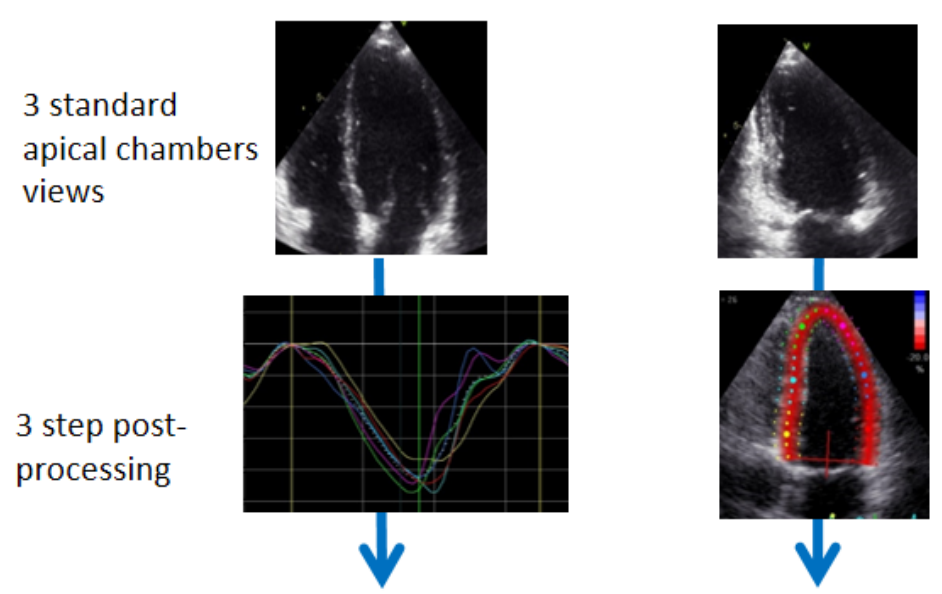

Layer specific
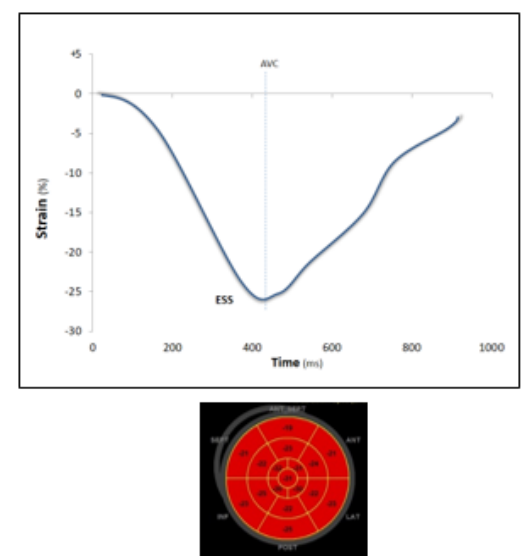
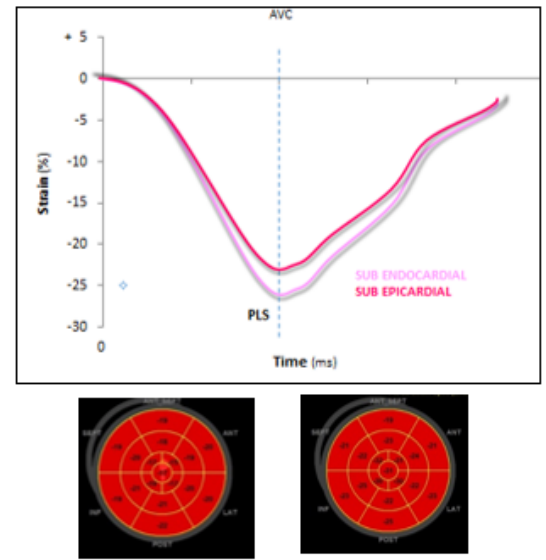

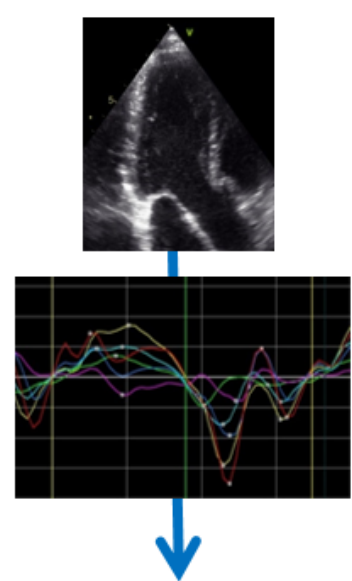

Systolic-diastolic SR

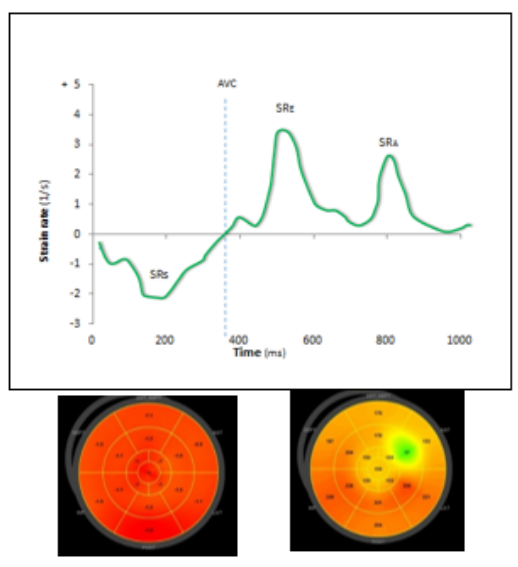



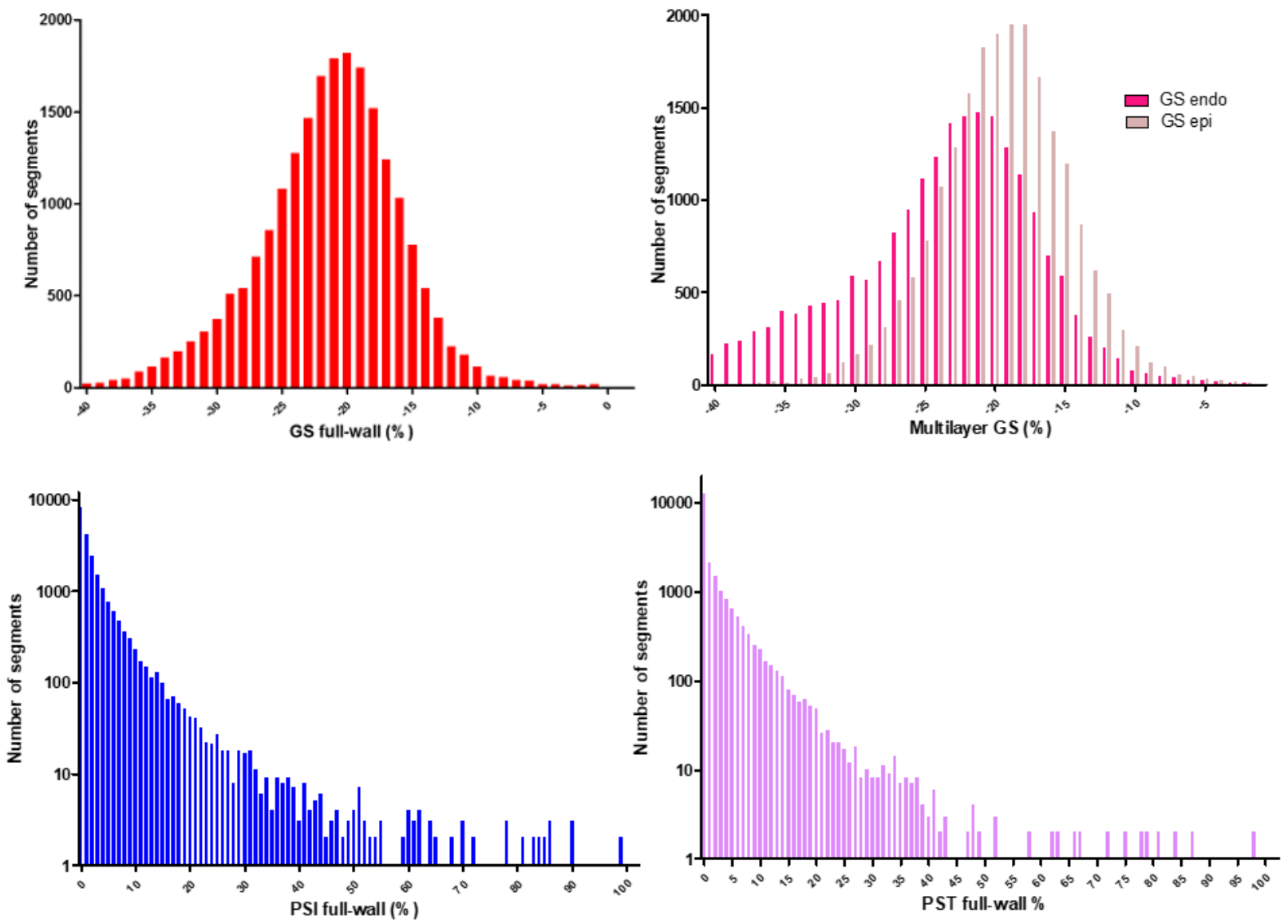
SUPPLEMENTAL MATERIAL

Table S1: Baseline characteristics of the study population

\begin{tabular}{|c|c|c|c|c|c|c|c|c|c|c|}
\hline \multirow[t]{2}{*}{ Characteristic } & \multirow[b]{2}{*}{$\mathbf{n}$} & \multicolumn{2}{|c|}{ Total $(\mathrm{N}=1243)$} & \multicolumn{2}{|c|}{ Men $(\mathrm{N}=590)$} & \multicolumn{2}{|c|}{ Women $(N=653)$} & \multirow[t]{2}{*}{ p-value } & \multicolumn{2}{|c|}{$\begin{array}{c}\begin{array}{c}\text { Subgroup of subjects with no } \\
\text { risk factors }\end{array} \\
(\mathrm{N}=441)\end{array}$} \\
\hline & & $\begin{array}{c}\text { Mean } \pm \mathbf{S D} / \\
\mathbf{n}(\%)\end{array}$ & Median (Q1 - Q3) & $\begin{array}{l}\text { Mean } \pm \mathbf{S D} / \\
\mathbf{n}(\%)\end{array}$ & Median (Q1 - Q3) & $\begin{array}{c}\text { Mean } \pm \text { SD } / \\
\text { n(\%) }\end{array}$ & Median (Q1 - Q3) & & Mean \pm SD $/ \mathbf{n}(\%)$ & Median (Q1 -Q3) \\
\hline Age (years, mean $\pm \mathrm{SD}$ ) & 1243 & $47 \pm 14$ & $54(33-59)$ & $48 \pm 14$ & $56(34-61)$ & $47 \pm 14$ & $52(33-58)$ & 0.001 & $43 \pm 14$ & $37(31-57)$ \\
\hline Height $(\mathrm{m}$, mean $\pm \mathrm{SD})$ & 1243 & $1.6 \pm 0.1$ & $1.6(1.6-1.7)$ & $1.7 \pm 0.0$ & $1.7(1.7-1.8)$ & $1.6 \pm 0.07$ & $1.6(1.5-1.6)$ & $<0.0001$ & $1.7 \pm 0.1$ & $1.7(1.6-1.8)$ \\
\hline Weight $(\mathrm{kg}$, mean $\pm \mathrm{SD})$ & 1243 & $73 \pm 14$ & $72(62-81)$ & $80 \pm 12$ & $78(72-87)$ & $66 \pm 12$ & $63(57-72)$ & $<0.0001$ & $64 \pm 9$ & $63(57-71)$ \\
\hline BMI $\left(\mathrm{kg} / \mathrm{m}^{2}\right.$, mean $\left.\pm \mathrm{SD}\right)$ & 1243 & $25 \pm 4$ & $25(22-28)$ & $26 \pm 4$ & $25(23-28)$ & $25 \pm 5$ & $24(22-27)$ & $<0.0001$ & $22 \pm 2$ & $23(21-24)$ \\
\hline Overweight (BMI>25) n (\%) & 1243 & $596(47.9 \%)$ & & $331(56.1 \%)$ & & $265(40.6 \%)$ & & $<0.0001$ & & \\
\hline $\begin{array}{l}\text { Systolic blood pressure, } \\
\mathrm{mmHg}\end{array}$ & 1243 & $125 \pm 15$ & $123(113-134)$ & $129 \pm 13$ & $128(120-137)$ & $120 \pm 14$ & $117(110-128)$ & $<0.0001$ & $119 \pm 12$ & $118(110-127)$ \\
\hline $\begin{array}{l}\text { Diastolic blood pressure, } \\
\mathrm{mmHg}\end{array}$ & 1243 & $72 \pm 9$ & $71(66-77)$ & $75 \pm 8$ & $74(69-79)$ & $69 \pm 8$ & $69(64-74)$ & $<0.0001$ & $70 \pm 8$ & $69(65-74)$ \\
\hline $\begin{array}{l}\text { Diabetes n (\%) } \\
\text { High blood pressure n (\%) }\end{array}$ & $\begin{array}{l}1055 \\
1055\end{array}$ & $\begin{array}{c}28(2.7 \%) \\
198(18.8 \%)\end{array}$ & & $\begin{array}{l}17(3.4 \%) \\
95(19.0 \%)\end{array}$ & & $\begin{array}{c}11(2.0 \%) \\
103(18.6 \%)\end{array}$ & & $\begin{array}{l}0.18 \\
0.87\end{array}$ & & \\
\hline Dyslipidemia n (\%) & 1055 & $236(22.4 \%)$ & & $123(24.6 \%)$ & & $113(20.4 \%)$ & & 0.1 & & \\
\hline Blood glucose, g/L & 1238 & $0.9 \pm 0.1$ & $0.8(0.8-0.9)$ & $0.9 \pm 0.1$ & $0.9(0.8-0.9)$ & $0.8 \pm 0.1$ & $0.8(0.8-0.9)$ & $<0.0001$ & $0.9 \pm 0.1$ & $0.8(0.8-0.9)$ \\
\hline Cholesterol level g/L & 1238 & $2.1 \pm 0.3$ & $2.1(1.8-2.4)$ & $2.0 \pm 0.3$ & $2.1(1.8-2.3)$ & $2.1 \pm 0.4$ & $2.1(1.8-2.4)$ & 0.002 & $2.1 \pm 0.4$ & $2.1(1.8-2.4)$ \\
\hline $\operatorname{LVEF}(\%)$ & 1162 & $65.1 \pm 6.3$ & $65.2(61.3-69.2)$ & $64.3 \pm 6.7$ & $64.7(60.4-68.7)$ & $65.8 \pm 5.9$ & $65.9(61.9-69.8)$ & 0.0002 & $64.6 \pm 6.4$ & $64.9(60.4-68.9)$ \\
\hline LVEDV (ml) & 1163 & $91.4 \pm 26.4$ & $87.5(73.2-106.3)$ & $104.4 \pm 27.1$ & $101.7(85.6-121.5)$ & $79.5 \pm 19.0$ & $77.9(66.5-91.3)$ & $<0.0001$ & $91.9 \pm 26.0$ & $87.3(73.7-106.2)$ \\
\hline LVEDV indexed (m1/m2) & 1163 & $49.6 \pm 12.5$ & $48.6(40.7-57.3)$ & $53.2 \pm 13.4$ & $52.4(43.8-61.6)$ & $46.3 \pm 10.5$ & $46.0(38.7-52.9)$ & $<0.0001$ & $52.7 \pm 12.3$ & $51.2(44.4-59.4)$ \\
\hline LVESV (ml) & 1160 & $32.2 \pm 11.8$ & $30.2(24.0-39.1)$ & $37.5 \pm 12.5$ & $35.8(28.4-45.2)$ & $27.4 \pm 8.6$ & $26.1(21.4-31.7)$ & $<0.0001$ & $32.9 \pm 12.0$ & $30.3(24.6-39.7)$ \\
\hline LVESV indexed (ml/m2) & 1160 & $17.4 \pm 5.7$ & $16.6(13.3-20.9)$ & $19.1 \pm 6.2$ & $18.3(14.3-22.9)$ & $15.9 \pm 4.9$ & $15.5(12.5-18.6)$ & $<0.0001$ & $18.8 \pm 6.0$ & $17.8(14.8-22.1)$ \\
\hline LVM (g) & 1127 & $136.6 \pm 39.9$ & $131.9(106.5-161.4)$ & $159.5 \pm 38.5$ & $155.7(133.7-181.5)$ & $116.6 \pm 28.8$ & $111.8(95.9-133.7)$ & $<0.0001$ & $123.0 \pm 35.6$ & $116.2(96.8-143.0)$ \\
\hline LVM indexed (g/m2) & 1127 & $74.0 \pm 17.5$ & $72.1(61.7-83.8)$ & $81.1 \pm 17.6$ & $78.8(69.9-90.9)$ & $67.7 \pm 14.9$ & $65.9(57.3-76.3)$ & $<0.001$ & $70.6 \pm 16.9$ & $68.1(60.0-80.1)$ \\
\hline $\mathrm{E}(\mathrm{m} / \mathrm{s})$ & 1185 & $0.7 \pm 0.1$ & $0.6(0.5-0.8)$ & $0.6 \pm 0.1$ & $0.6(0.5-0.7)$ & $0.7 \pm 0.1$ & $0.6(0.6-0.8)$ & $<0.0001$ & $0.7 \pm 0.2$ & $0.7(0.6-0.8)$ \\
\hline $\mathrm{A}(\mathrm{m} / \mathrm{s})$ & 1184 & $0.6 \pm 0.1$ & $0.6(0.4-0.7)$ & $0.6 \pm 0.1$ & $0.5(0.4-0.6)$ & $0.6 \pm 0.1$ & $0.6(0 .-0.7)$ & 0.0004 & $0.6 \pm 0.1$ & $0.5(0.5-0.6)$ \\
\hline E/A (No unit) & 1184 & $1.2 \pm 0.4$ & $1.1(0.8-1.4)$ & $1.2 \pm 0.4$ & $1.1(0.8-1.4)$ & $1.2 \pm 0.4$ & $1.1(0.9-1.5)$ & 0.085 & $1.3 \pm 0.4$ & $1.3(1.0-1.6)$ \\
\hline DT E (ms) & 1185 & $210.2 \pm 52.5$ & $206.2(173.5-240.5)$ & $217.8 \pm 55.6$ & $214.7(179.8-253.1)$ & $203.5 \pm 48.6$ & $199.7(168.6-233.3)$ & $<0.0001$ & $208.5 \pm 52.1$ & $206.2(170.5-242.0)$ \\
\hline $\begin{array}{l}E^{\prime}(\mathrm{cm} / \mathrm{s}) \\
E^{\prime} / E^{\prime} \text { (No unit) }\end{array}$ & $\begin{array}{l}1185 \\
1181\end{array}$ & $\begin{array}{c}11.7 \pm 3.2 \\
6.4 \pm 5.2\end{array}$ & $\begin{aligned} 11.2 & (9.2-14.0) \\
6.0 & (5.1-7.1)\end{aligned}$ & $\begin{array}{c}11.4 \pm 3.1 \\
6.4 \pm 7.4\end{array}$ & $\begin{array}{c}10.9(9.1-13.6) \\
5.8(4.9-7.0)\end{array}$ & $\begin{array}{c}11.9 \pm 3.3 \\
6.3 \pm 1.6\end{array}$ & $\begin{array}{c}11.4(9.4-14.8) \\
6.2(5.2-7.3)\end{array}$ & $\begin{array}{c}0.01 \\
0.003\end{array}$ & $\begin{array}{c}13.1 \pm 3.2 \\
5.7 \pm 1.4\end{array}$ & $\begin{array}{c}13.1(10.5-15.4) \\
5.5(4.7-6.4)\end{array}$ \\
\hline LA volume (ml) & 1176 & $40.7 \pm 13.7$ & $39.0(31.0-48.3)$ & $44.5 \pm 14.3$ & $43.0(34.8-53.1)$ & $37.1 \pm 12.1$ & $36.0(28.4-43.7)$ & $<0.0001$ & $37.4 \pm 13.4$ & $35.1(28.2-43.6)$ \\
\hline LA volume indexed $\left(\mathrm{ml} / \mathrm{m}^{2}\right)$ & 1176 & $22.1 \pm 6.7$ & $21.3(17.4-25.9)$ & $22.6 \pm 7.0$ & $21.8(17.8-26.3)$ & $21.5 \pm 6.5$ & $21.1(17.0-25.5)$ & 0.009 & $21.5 \pm 7.1$ & $20.7(16.5-25.5)$ \\
\hline
\end{tabular}

BMI, body mass index; $S D$, standard deviation; $L V E F$, left ventricular ejection fraction; $L V E D V, L V$ end-diastolic volume; $L V E S V L V$ end-systolic volume, , $L V M L V$ mass;

LA Left atrium 
Table S2: Left ventricular deformation parameters according to gender

\begin{tabular}{|c|c|c|c|c|c|c|c|c|c|}
\hline \multirow[b]{2}{*}{ 2D Deformation value } & \multicolumn{2}{|c|}{ Total $(\mathrm{N}=\mathbf{1 2 4 3})$} & \multicolumn{2}{|c|}{ Men $(\mathbf{N}=\mathbf{5 9 0})$} & \multicolumn{2}{|c|}{ Women $(\mathrm{N}=\mathbf{6 5 3})$} & \multicolumn{3}{|c|}{$\begin{array}{l}\text { Subgroup of subjects with no risk factors } \\
(\mathrm{N}=\mathbf{4 4 1})\end{array}$} \\
\hline & Mean+SD & Median(Q1-Q3) & Mean+SD & $\operatorname{Median}(Q 1-Q 3)$ & Mean+SD & Median(Q1-Q3) & P-value & Mean+SD & Median(Q1-Q3) \\
\hline \multicolumn{10}{|c|}{ Global multilayer longitudinal strain values $(n=1243)$} \\
\hline GSendo \% & $-23.4 \pm 2.7$ & $-23.5(-25.2--21.5)$ & -22.82 .6 & $-22.9(-24.5--21.0)$ & $-24.0 \pm 2.7$ & $-24.1(-26.0--22.1)$ & $<0.0001$ & $-23.8 \pm 2.6$ & $-23.9(-25.7--22.0)$ \\
\hline GSfull-wall \% & $-21.1 \pm 2.5$ & $-21.2(-22.8--19.4)$ & $-20.5 \pm 2.4$ & $-20.5(-22.2-19.0)$ & $-21.7 \pm 2.5$ & $-21.7(-23.4--19.8)$ & $<0.0001$ & $-21.5 \pm 2.4$ & $-21.5(-23.2--19.7)$ \\
\hline GSepi \% & $-19.1 \pm 2.5$ & $-19.1(-20.8--17.4)$ & $-18.5 \pm 2.3$ & $-18.5(-20.2--17.0)$ & $-19.7 \pm 2.5$ & $-19.7(-21.3--18.0)$ & $<0.0001$ & $-19.4 \pm 2.4$ & $-19.4(-21.0--17.7)$ \\
\hline GSendo/ GSepi ratio & $1.2 \pm 0.0$ & $1.1(1.1-1.2)$ & $1.2 \pm 0.0$ & $1.2(1.1-1.2)$ & $1.2 \pm 0.0$ & $1.2(1.1-1.2)$ & 0.059 & $1.23 \pm 0.08$ & $1.22(1.18-1.27)$ \\
\hline GSendo Base-apex ratio & $0.66 \pm 0.12$ & $0.65(0.58-0.72)$ & $0.64 \pm 0.11$ & $0.64(0.57-0.72)$ & $0.67 \pm 0.12$ & $0.66(0.59-0.73)$ & 0.001 & $0.67 \pm 0.11$ & $0.66(0.59-0.73)$ \\
\hline $\begin{array}{l}\text { GSfull-wall Base- apex } \\
\text { ratio }\end{array}$ & $0.79 \pm 0.14$ & $0.79(0.70-0.87)$ & $0.78 \pm 0.13$ & $0.78(0.69-0.86)$ & $0.81 \pm 0.14$ & $0.80(0.71-0.89)$ & 0.004 & $0.81 \pm 0.13$ & $0.80(0.72-0.88)$ \\
\hline GSepi Base-apex ratio & $0.94 \pm 0.18$ & $0.93(0.82-1.05)$ & $0.93 \pm 0.17$ & $0.92(0.82-1.02)$ & $0.96 \pm 0.18$ & $0.94(0.82-1.06)$ & 0.024 & $0.96 \pm 0.17$ & $0.94(0.84-1.06)$ \\
\hline \multicolumn{10}{|c|}{ Global longitudinal strain rate values $(\mathrm{n}=\mathbf{1 2 4 3})$} \\
\hline GSRs $1 /$ sec & $-1.1 \pm 0.2$ & $-1.1(-1.2-1.0)$ & $-1.1 \pm 0.1$ & $-1.1(-1.2-1.0)$ & $-1.1 \pm 0.1$ & $-1.1(-1.2-1.0)$ & 0.21 & $-1.13 \pm 0.16$ & $-1.13(-1.23--1.00)$ \\
\hline GSRe 1/sec & $1.4 \pm 0.4$ & $1.3(1.1-1.6)$ & $1.2 \pm 0.3$ & $1.2(1.00-1.50)$ & $1.5 \pm 0.4$ & $1.4(1.20-1.7)$ & $<0.0001$ & $1.53 \pm 0.41$ & $1.53(1.27-1.80)$ \\
\hline GSRa $1 /$ sec & $0.9 \pm 0.2$ & $0.9(0.7-1.0)$ & $0.9 \pm 0.2$ & $0.9(0.7-1.0)$ & $0.9 \pm 0.2$ & $0.8(0.7-1.0)$ & 0.44 & $0.79 \pm 0.25$ & $0.75(0.60-0.97)$ \\
\hline
\end{tabular}

Table S3: Left ventricular longitudinal deformation parameters according to age 


\begin{tabular}{|c|c|c|c|c|c|c|c|c|c|}
\hline \multirow[t]{2}{*}{ Characteristic } & \multicolumn{3}{|c|}{$\begin{array}{c}\text { 20-40 years } \\
n=508\end{array}$} & \multicolumn{2}{|l|}{$\begin{array}{l}\text { 40-60 years } \\
n=423\end{array}$} & \multicolumn{2}{|l|}{$\begin{array}{c}>60 \text { years } \\
\mathbf{n}=309\end{array}$} & \multicolumn{2}{|c|}{$\begin{array}{l}\text { Subgroup of subjects with no risk } \\
\text { factors }(n=441)\end{array}$} \\
\hline & Mean+SD & Median(Q1-Q3) & Mean+SD & Median(Q1-Q3) & Mean+SD & Median(Q1-Q3) & P-value & Mean+SD & Median(Q1-Q3) \\
\hline \multicolumn{10}{|c|}{ Global multilayer longitudinal strain values $(n=1243)$} \\
\hline GSendo \% & $-23.25 \pm 2.45$ & $-23.23(-24.77--21.47)$ & $-23.46 \pm 2.90$ & $-23.50(-25.50--21.57)$ & $-23.64 \pm 2.85$ & $-23.83(-25.53--21.70)$ & 0.13 & $-23.83 \pm 2.62$ & $-23.87(-25.67--22.03)$ \\
\hline GSfull-wall \% & $-20.99 \pm 2.28$ & $-21.07(-22.50--19.33)$ & $-21.18 \pm 2.66$ & $-21.17(-22.90--19.37)$ & $-21.27 \pm 2.72$ & $-21.33(-23.17--19.47)$ & 0.25 & $-21.46 \pm 2.42$ & $-21.53(-23.20--19.70)$ \\
\hline GSepi \% & $-19.01 \pm 2.23$ & $-18.97(-20.60--17.47)$ & $-19.20 \pm 2.55$ & $-19.17(-20.97--17.50)$ & $-19.23 \pm 2.71$ & $-19.37(-21.17--17.33)$ & 0.36 & $-19.40 \pm 2.37$ & $-19.37(-21.03--17.70)$ \\
\hline GSendo/ GSepi ratio & $1.23 \pm 0.07$ & $1.21(1.18-1.26)$ & $1.23 \pm 0.08$ & $1.21(1.17-1.26)$ & $1.24 \pm 0.09$ & $1.21(1.18-1.29)$ & 0.51 & $1.23 \pm 0.08$ & $1.22(1.18-1.27)$ \\
\hline GSendo Base-apex ratio & $0.68 \pm 0.11$ & $0.68(0.60-0.74)$ & $0.66 \pm 0.13$ & $0.65(0.57-0.73)$ & $0.62 \pm 0.11$ & $0.62(0.54-0.69)$ & $<0.0001$ & $0.67 \pm 0.11$ & $0.66(0.59-0.73)$ \\
\hline $\begin{array}{l}\text { GSfull-wall Base-apex } \\
\text { ratio }\end{array}$ & $0.82 \pm 0.13$ & $0.81(0.72-0.89)$ & $0.79 \pm 0.15$ & $0.79(0.69-0.87)$ & $0.76 \pm 0.13$ & $0.76(0.67-0.84)$ & $<0.0001$ & $0.81 \pm 0.13$ & $0.80(0.72-0.88)$ \\
\hline GSepi Base-apex ratio & $0.96 \pm 0.17$ & $0.94(0.84-1.06)$ & $0.94 \pm 0.19$ & $0.92(0.80-1.05)$ & $0.92 \pm 0.18$ & $0.90(0.79-1.02)$ & 0.0007 & $0.96 \pm 0.17$ & $0.94(0.84-1.06)$ \\
\hline \multicolumn{10}{|c|}{ Global longitudinal strain rate values $(n=1243)$} \\
\hline GSRs 1/sec & $-1.11 \pm 0.15$ & $-1.10(-1.20--1.00)$ & $-1.11 \pm 0.17$ & $-1.10(-1.20--1.00)$ & $-1.14 \pm 0.19$ & $-1.17(-1.27--1.03)$ & 0.096 & $-1.13 \pm 0.16$ & $-1.13(-1.23--1.00)$ \\
\hline GSRe 1/sec & $1.61 \pm 0.36$ & $1.60(1.33-1.83)$ & $1.28 \pm 0.33$ & $1.23(1.03-1.50)$ & $1.14 \pm 0.27$ & $1.10(0.93-1.33)$ & $<0.0001$ & $1.53 \pm 0.41$ & $1.53(1.27-1.80)$ \\
\hline GSRa 1/sec & $0.71 \pm 0.21$ & $0.67(0.57-0.82)$ & $0.93 \pm 0.20$ & $0.93(0.80-1.07)$ & $1.02 \pm 0.22$ & $1.03(0.90-1.17)$ & $<0.0001$ & $0.79 \pm 0.25$ & $0.75(0.60-0.97)$ \\
\hline
\end{tabular}

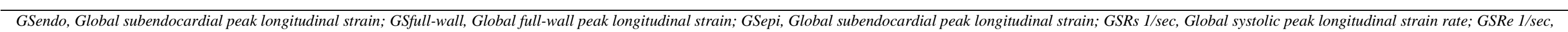
Global early diastolic peak longitudinal strain rate; GSRa 1/sec Global late diastolic peak longitudinal strain rate; $p^{*}$ non parametric test

Table S4: Baseline characteristics before and after weighting of the population used for weighting $(\mathrm{N}=1222)$ 


\begin{tabular}{|c|c|c|c|c|c|c|c|c|}
\hline \multirow[t]{3}{*}{ Characteristic } & \multicolumn{4}{|l|}{ Before weighting } & \multicolumn{4}{|l|}{ After weighting } \\
\hline & \multirow{2}{*}{$\begin{array}{l}\text { Dyspnea No } \\
(\mathrm{N}=1052) \\
\text { Mean } \pm \mathrm{SD} / \\
\text { median(Q1-Q3) }\end{array}$} & \multicolumn{3}{|l|}{$\begin{array}{l}\text { Dyspnea Yes } \\
(\mathrm{N}=170)\end{array}$} & \multirow{2}{*}{$\begin{array}{l}\text { Dyspnea No } \\
(\mathrm{N}=1052) \\
\text { Mean } \pm \text { SD/ } \\
\text { median }(Q 1-Q 3 \\
\end{array}$} & \multicolumn{3}{|l|}{$\begin{array}{l}\text { Dyspnea Yes } \\
(\mathbf{N}=170)\end{array}$} \\
\hline & & $\begin{array}{l}\text { Mean } \pm \text { SD/ } \\
\text { median }(Q 1-Q 3\end{array}$ & ASMD & P-value & & $\begin{array}{l}\text { Mean } \pm \text { SD/ } \\
\text { median }(Q 1-Q 3\end{array}$ & ASMD & $\begin{array}{l}\text { P- } \\
\text { value }\end{array}$ \\
\hline Age (years, mean $\pm \mathrm{SD}$ ) & $53(34-60)$ & $57(39-62)$ & $36.90 \%$ & $<0.0001$ & $55(34-60)$ & $53(34-60)$ & $6.50 \%$ & 0.43 \\
\hline Height $(\mathrm{m}$, mean $\pm \mathrm{SD})$ & $1.69 \pm 0.09$ & $1.66 \pm 0.10$ & $39.70 \%$ & $<0.0001$ & $1.69 \pm 0.09$ & $1.69 \pm 0.11$ & $2.70 \%$ & 0.75 \\
\hline Weight $(\mathrm{Kg}$, mean $\pm \mathrm{SD})$ & $72(62-81)$ & $73(61-85)$ & $9.60 \%$ & 0.24 & $72(62-81)$ & $73(60-83)$ & $0.70 \%$ & 0.93 \\
\hline $\mathrm{BMI}\left(\mathrm{Kg} / \mathrm{m}^{2}\right.$, mean $\left.\pm \mathrm{SD}\right)$ & $25(22-27)$ & $27(23-30)$ & $39.70 \%$ & $<0.0001$ & $25(22-28)$ & $25(22-28)$ & $2.40 \%$ & 0.77 \\
\hline $\mathrm{WC}(\mathrm{cm})$ & $87.90 \pm 12.18$ & $91.05 \pm 13.10$ & $25.60 \%$ & 0.002 & $88.32 \pm 12.37$ & $88.80 \pm 12.08$ & $3.90 \%$ & 0.64 \\
\hline Systolic blood pressure, $\mathrm{mmHg}$ & $123(114-134)$ & $124(112-134)$ & $3.60 \%$ & 0.96 & $123(114-134)$ & $124(112-134)$ & $0.50 \%$ & 0.95 \\
\hline Diastolic blood pressure, $\mathrm{mmHg}$ & $72 \pm 9$ & $71 \pm 9$ & $4.90 \%$ & 0.55 & $72 \pm 9$ & $72 \pm 9$ & $0.30 \%$ & 0.98 \\
\hline Heart rate (bpm) & $63 \pm 9$ & $65 \pm 9$ & $19.30 \%$ & 0.02 & $64 \pm 9$ & $64 \pm 9$ & $4.20 \%$ & 0.61 \\
\hline Total Cholesterol level, g/L & $2.13 \pm 0.39$ & $2.16 \pm 0.40$ & $8.70 \%$ & 0.29 & $2.13 \pm 0.39$ & $2.14 \pm 0.40$ & $2.00 \%$ & 0.81 \\
\hline HDL Cholesterol level, g/L & $0.57(0.48-0.67)$ & $0.56(0.46-0.67)$ & $6.30 \%$ & 0.57 & $0.57(0.48-0.66)$ & $0.56(0.47-0.67)$ & $4.90 \%$ & 0.55 \\
\hline LDL Cholesterol level, g/L & $1.35 \pm 0.34$ & $1.36 \pm 0.35$ & $4.20 \%$ & 0.61 & $1.35 \pm 0.34$ & $1.36 \pm 0.35$ & $2.40 \%$ & 0.77 \\
\hline Triglyceride level, g/L & $0.88(0.65-1.18)$ & $1.01(0.73-1.44)$ & $29.10 \%$ & 0.0007 & $0.90(0.66-1.21)$ & $0.90(0.68-1.36)$ & $6.40 \%$ & 0.44 \\
\hline Blood glucose, (g/L) & $0.88(0.82-0.94)$ & $0.89(0.84-0.96)$ & $20.00 \%$ & 0.026 & $0.88(0.82-0.94)$ & $0.88(0.83-0.93)$ & $5.10 \%$ & 0.54 \\
\hline $\begin{array}{l}\text { eGFR (MDRD formula) } \\
(\mathrm{mL} / \mathrm{min} / 1.73 \mathrm{~m} 2)\end{array}$ & $96.63 \pm 16.92$ & $93.17 \pm 18.81$ & $20.10 \%$ & 0.015 & $96.13 \pm 17.04$ & $96.79 \pm 18.22$ & $3.80 \%$ & 0.64 \\
\hline Female gender & $527(50 \%)$ & $114(67 \%)$ & $35.00 \%$ & $<0.0001$ & $552(52 \%)$ & $88(52 \%)$ & $1.60 \%$ & 0.85 \\
\hline Current smoker & $241(23 \%)$ & $43(25 \%)$ & $5.60 \%$ & 0.49 & $246(23 \%)$ & $45(26 \%)$ & $7.10 \%$ & 0.38 \\
\hline Overweight (BMI > 25) & $480(46 \%)$ & $107(63 \%)$ & $35.30 \%$ & $<0.0001$ & $500(48 \%)$ & $89(52 \%)$ & $9.70 \%$ & 0.24 \\
\hline Diabetes Mellitus & $27(3 \%)$ & $9(5 \%)$ & $14.10 \%$ & 0.051 & $29(3 \%)$ & $3(2 \%)$ & $4.70 \%$ & 0.59 \\
\hline HTA self-reported by patient & $153(15 \%)$ & $48(28 \%)$ & $33.90 \%$ & $<0.0001$ & $172(16 \%)$ & $28(16 \%)$ & $0.10 \%$ & 0.99 \\
\hline Dyslipidemia & $214(20 \%)$ & $54(32 \%)$ & $26.20 \%$ & 0.0008 & $232(22 \%)$ & $39(23 \%)$ & $2.30 \%$ & 0.78 \\
\hline Sartan & $66(6 \%)$ & $15(9 \%)$ & $9.70 \%$ & 0.22 & $69(7 \%)$ & $10(6 \%)$ & $3.80 \%$ & 0.65 \\
\hline Beta blockers & $52(5 \%)$ & $15(9 \%)$ & $15.40 \%$ & 0.039 & $57(5 \%)$ & $8(4 \%)$ & $4.50 \%$ & 0.59 \\
\hline Diuretics & $46(4 \%)$ & $11(6 \%)$ & $9.30 \%$ & 0.23 & $49(5 \%)$ & $7(4 \%)$ & $3.60 \%$ & 0.67 \\
\hline IEC & $27(3 \%)$ & $9(5 \%)$ & $14.10 \%$ & 0.051 & $31(3 \%)$ & $5(3 \%)$ & $1.90 \%$ & 0.82 \\
\hline
\end{tabular}




\begin{tabular}{|c|c|c|c|c|c|c|c|c|c|}
\hline & \multicolumn{2}{|c|}{ Entire population(N=1243) } & \multicolumn{4}{|l|}{ Age (years) } & \multicolumn{3}{|l|}{ Gender } \\
\hline & Mean \pm SD & Median (Q1 - Q3) & $\begin{array}{l}\mathbf{2 0 - 4 0} \\
(\mathbf{N}=\mathbf{5 0 3}) \\
\text { Mean+SD/ } \\
\text { median (Q1 - Q3) }\end{array}$ & $\begin{array}{l}\mathbf{4 0 - 6 0} \\
(\mathbf{N}=\mathbf{3 9 9}) \\
\text { Mean+SD/ } \\
\text { median (Q1 - Q3) }\end{array}$ & $\begin{array}{l}>\mathbf{6 0} \\
(\mathbf{N}=\mathbf{3 3 9}) \\
\text { Mean+SD/ } \\
\text { median }(\mathrm{Q} 1-\mathrm{Q} 3)\end{array}$ & P-value & $\begin{array}{l}\text { Men } \\
(\mathbf{N}=\mathbf{5 9 0}) \\
\text { Mean+SD/ } \\
\text { median (Q1 - Q3) }\end{array}$ & $\begin{array}{l}\text { Women } \\
(\mathbf{N}=\mathbf{6 5 3}) \\
\text { Mean+SD/ } \\
\text { median }(\mathrm{Q} 1 \text { - Q3) }\end{array}$ & P-value \\
\hline \multicolumn{10}{|c|}{ Global multilayer longitudinal strain values $(n=1243)$} \\
\hline GSendo \% & $-23.41 \pm 2.72$ & $-23.5(-25.2--21.5)$ & $-23.25 \pm 2.45$ & $-23.46 \pm 2.90$ & $-23.64 \pm 2.85$ & 0.093 & $-22.77 \pm 2.56$ & $-24.00 \pm 2.73$ & $<0.0001$ \\
\hline GSfull-wall \% & $-21.12 \pm 2.53$ & $-21.2(-22.8--19.4)$ & $-20.99 \pm 2.28$ & $-21.18 \pm 2.66$ & $-21.27 \pm 2.72$ & 0.20 & $-20.50 \pm 2.36$ & $-21.68 \pm 2.54$ & $<0.0001$ \\
\hline GSepi \% & $-19.13 \pm 2.47$ & $-19.1(-20.8--17.4)$ & $-19.01 \pm 2.23$ & $-19.20 \pm 2.55$ & $-19.23 \pm 2.71$ & 0.30 & $-18.53 \pm 2.31$ & $-19.66 \pm 2.48$ & $<0.0001$ \\
\hline GSendo/ GSepi ratio & $1.23 \pm 0.08$ & $1.21(1.18-1.27)$ & $1.21(1.18-1.26)$ & $1.21(1.17-1.26)$ & $1.21(1.18-1.29)$ & 0.38 & $1.21(1.18-1.28)$ & $1.21(1.17-1.26)$ & 0.059 \\
\hline $\begin{array}{l}\text { GSendo Base apex } \\
\text { ratio }\end{array}$ & $0.66 \pm 0.12$ & $0.65(0.58-0.72)$ & $0.68(0.60-0.74)$ & $0.65(0.57-0.73)$ & $0.62(0.54-0.69)$ & $<0.0001$ & $0.64(0.57-0.72)$ & $0.66(0.59-0.73)$ & 0.001 \\
\hline $\begin{array}{l}\text { GSfull-wall Base } \\
\text { apex ratio }\end{array}$ & $0.79 \pm 0.14$ & $0.79(0.70-0.87)$ & $0.81(0.72-0.89)$ & $0.79(0.69-0.88)$ & $0.76(0.67-0.84)$ & $<0.0001$ & $0.78(0.69-0.86)$ & $0.80(0.71-0.89)$ & 0.004 \\
\hline $\begin{array}{l}\text { GSepi Base apex } \\
\text { ratio }\end{array}$ & $0.94 \pm 0.18$ & $0.93(0.82-1.05)$ & $0.94(0.84-1.06)$ & $0.93(0.81-1.05)$ & $0.90(0.79-1.02)$ & 0.001 & $0.92(0.82-1.02)$ & $0.94(0.82-1.06)$ & 0.024 \\
\hline \multicolumn{10}{|c|}{ Global longitudinal strain rate values $(n=1243)$} \\
\hline GSRs $1 /$ sec & $-1.12 \pm 0.17$ & $-1.10(-1.20--1.00$ & $-1.10(-1.20--1.00)$ & $-1.10(-1.20--1.00)$ & $-1.13(-1.27--1.00)$ & 0.005 & $-1.10(-1.20--1.00)$ & $\begin{array}{l}-1.10(-1.23-- \\
1.00)\end{array}$ & 0.21 \\
\hline GSRe 1/sec & $1.38 \pm 0.39$ & $1.33(1.07-1.63)$ & $1.60(1.33-1.83)$ & $1.23(1.03-1.50)$ & $1.10(0.97-1.33)$ & $<0.0001$ & $1.23(1.00-1.50)$ & $1.47(1.20-1.73)$ & $<0.0001$ \\
\hline GSRa 1/sec & $0.86 \pm 0.25$ & $0.87(0.67-1.03)$ & $0.67(0.57-0.80)$ & $0.93(0.80-1.07)$ & $1.03(0.87-1.17)$ & $<0.0001$ & $0.87(0.70-1.03)$ & $0.83(0.67-1.03)$ & 0.44 \\
\hline
\end{tabular}

GSendo, Global subendocardial peak longitudinal strain; GSfull-wall, Global full-wall peak longitudinal strain; GSepi, Global subendocardial peak longitudinal strain; GSRs 1/sec, Global systolic peak longitudinal strain rate; GSRe 1/sec, Global early diastolic peak longitudinal strain rate; GSRa 1/sec, Global late diastolic peak longitudinal strain rate; 
Table S6: Tracking feasibility

\begin{tabular}{|c|c|c|c|c|}
\hline View & $\begin{array}{l}\mathbf{N} \\
\text { available } \\
\text { values } \\
\end{array}$ & $\begin{array}{l}\mathbf{N} \\
\text { missing } \\
\text { values }\end{array}$ & $\begin{array}{l}\% \text { missing out of } \\
\text { measured values }\end{array}$ & $\begin{array}{l}\text { \% missing } \\
\text { out of } 1243 \text { values }\end{array}$ \\
\hline \multicolumn{5}{|l|}{ 4-Chamber view } \\
\hline Apical Lateral & 1181 & 58 & $58(4.7 \%)$ & $58(4.7 \%)$ \\
\hline Mid Lateral & 1175 & 64 & $64(5.2 \%)$ & $64(5.1 \%)$ \\
\hline Mid Septal & 1235 & 4 & $4(0.3 \%)$ & $4(0.3 \%)$ \\
\hline Apical Septal & 1229 & 10 & $10(0.8 \%)$ & $10(0.8 \%)$ \\
\hline Basal Lateral & 1002 & 237 & $237(19.1 \%)$ & $237(19.1 \%)$ \\
\hline basSept & 1180 & 59 & $59(4.8 \%)$ & $59(4.7 \%)$ \\
\hline \multicolumn{5}{|l|}{ 2-Chamber view } \\
\hline Apical Inferior & 1123 & 28 & $28(2.4 \%)$ & $28(2.3 \%)$ \\
\hline Mid Anterolateral & 1041 & 110 & $110(9.6 \%)$ & $110(8.8 \%)$ \\
\hline Mid Inferior & 1146 & 5 & $5(0.4 \%)$ & $5(0.4 \%)$ \\
\hline Apical Anterolateral & 1029 & 122 & $122(10.6 \%)$ & $122(9.8 \%)$ \\
\hline Basal Anterolateral & 952 & 199 & $199(17.3 \%)$ & $199(16.0 \%)$ \\
\hline Basal Inferior & 1092 & 59 & $59(5.1 \%)$ & $59(4.7 \%)$ \\
\hline \multicolumn{5}{|l|}{ 3-chamber view } \\
\hline Mid AntetoSeptal & 1099 & 41 & $41(3.6 \%)$ & $41(3.3 \%)$ \\
\hline Mid Posterior & 1114 & 26 & $26(2.3 \%)$ & $26(2.1 \%)$ \\
\hline Apical AnteroSeptal & 1047 & 93 & $93(8.2 \%)$ & $93(7.5 \%)$ \\
\hline Apical Posterior & 1064 & 76 & $76(6.7 \%)$ & $76(6.1 \%)$ \\
\hline Basal AnteroSeptal & 1019 & 121 & $121(10.6 \%)$ & $121(9.7 \%)$ \\
\hline Basal Posterior & 858 & 282 & $282(24.7 \%)$ & $282(22.7 \%)$ \\
\hline
\end{tabular}


Table S7: Comparison of strain values according to the type of apical chamber view acquisition and according to the method of calculation of the global longitudinal strain value (only available for GSendo, GSfull-wall and GSepi).

\section{TYPE OF CHAMBER VIEW ACQUISITION}

METHOD OF GLOBAL STRAIN

\section{CALCULATION ${ }^{1}$}

\section{GLOBAL}

Mean \pm SEM

\begin{tabular}{ccc}
\hline $4 \mathrm{CH}$ & $2 \mathrm{CH}$ & $3 \mathrm{CH}$ \\
Mean \pm SEM & Mean \pm SEM & Mean \pm SEM \\
$\mathrm{N}=1236$ & $\mathrm{~N}=1154$ & $\mathrm{~N}=1141$
\end{tabular}
P: $4 \mathrm{ch} 2 \mathrm{ch}$ $3 \mathrm{CH} /$

P : Global-4Ch
myocardial line averaging

segmental

averaging

\section{$P$ value}

Global multilayer longitudinal strain values

\begin{tabular}{|c|c|c|c|c|c|c|c|c|c|}
\hline GSendo \% & $-23.41 \pm 0.09$ & $-23.07 \pm 0.09$ & $-23.61 \pm 0.09$ & $-23.59 \pm 0.10$ & $<0.0001$ & $<0.0001$ & $-23.41 \pm 0.08$ & $-24.17 \pm 0.08$ & $<0.0001$ \\
\hline GSfull-wall \% & $-21.12 \pm 0.07$ & $-20.79 \pm 0.08$ & $-21.52 \pm 0.09$ & $-21.13 \pm 0.09$ & $<0.0001$ & $<0.0001$ & $-21.12 \pm 0.07$ & $-21.47 \pm 0.07$ & $<0.0001$ \\
\hline GSepi \% & $-19.23 \pm 0.07$ & $-18.80 \pm 0.08$ & $-19.70 \pm 0.09$ & $-19.01 \pm 0.09$ & $<0.0001$ & $<0.0001$ & $-19.13 \pm 0.07$ & $-19.41 \pm 0.07$ & $<0.0001$ \\
\hline
\end{tabular}

Global longitudinal strain rate values $(n=1243)$

\begin{tabular}{|c|c|c|c|c|c|c|c|c|c|}
\hline GSRs 1/sec & $-1.12 \pm 0.004$ & $-1.09 \pm 0.01$ & $-1.14 \pm 0.01$ & $-1.13 \pm 0.01$ & $<0.0001$ & $<0.0001$ & ND & ND & ND \\
\hline GSRe 1/sec & $1.38 \pm 0.01$ & $1.38 \pm 0.01$ & $1.35 \pm 0.01$ & $1.39 \pm 0.01$ & 0.0003 & 0.15 & ND & ND & ND \\
\hline GSRa 1/sec & $0.86 \pm 0.01$ & $0.84 \pm 0.01$ & $0.83 \pm 0.01$ & $0.89 \pm 0.01$ & $<0.0001$ & $<0.0021$ & ND & ND & ND \\
\hline
\end{tabular}

\footnotetext{
${ }^{1}$ Values were computed as the number of points within the myocardial line or by averaging the values computed at the segmental level from the same frame

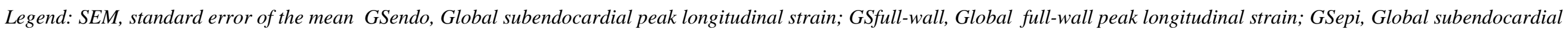

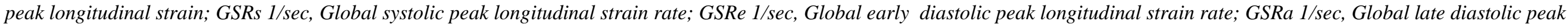
longitudinal strain rate;; P from mixed model.
} 
Table S8: Baseline echocardiographic characteristics and left ventricular deformation parameters according to HF stage

\begin{tabular}{|c|c|c|c|c|c|c|c|}
\hline \multirow[b]{2}{*}{ Parameter } & \multicolumn{2}{|c|}{ Stage $0(n=441)$} & \multicolumn{2}{|c|}{ Stage A $(n=573)$} & \multicolumn{2}{|c|}{ Stage $B(n=141)$} & \multirow[b]{2}{*}{ P-value } \\
\hline & Mean \pm SD & Median (Q1 - Q3) & Mean \pm SD & Median (Q1 - Q3) & Mean \pm SD & Median (Q1 - Q3) & \\
\hline LVEF (\%) & $64.59 \pm 6.41$ & $64.89(60.41-68.90)$ & $65.69 \pm 6.17$ & $65.47(61.83-69.71)$ & $64.03 \pm 6.98$ & $65.26(60.61-68.22)$ & 0.029 \\
\hline LV End-diastolic volume $\left(\mathrm{ml} / \mathrm{m}^{2}\right)$ & $52.60 \pm 12.28$ & $51.25(44.38-59.33)$ & $46.20 \pm 10.32$ & $46.08(38.71-53.37)$ & $57.63 \pm 15.71$ & $57.99(45.32-67.45)$ & $<0.0001$ \\
\hline LV End-systolic volume $\left(\mathrm{ml} / \mathrm{m}^{2}\right)$ & $18.79 \pm 5.98$ & $17.82(14.78-22.16)$ & $15.98 \pm 4.67$ & $15.36(12.39-19.12)$ & $20.86 \pm 7.27$ & $20.12(14.29-25.41)$ & $<0.0001$ \\
\hline LV mass index ASE $\left(g / \mathrm{m}^{2}\right) 2 D$ & $70.49 \pm 16.93$ & $68.37(59.42-79.91)$ & $71.84 \pm 13.31$ & $72.28(62.29-81.39)$ & $98.59 \pm 18.63$ & $98.77(88.50-109.11)$ & $<0.0001$ \\
\hline Left atrial volume index $\left(\mathrm{ml} / \mathrm{m}^{2}\right)$ & $21.48 \pm 7.06$ & $20.66(16.51-25.39)$ & $22.31 \pm 6.54$ & $21.70(18.03-25.94)$ & $24.74 \pm 7.18$ & $24.29(19.62-28.85)$ & $<0.0001$ \\
\hline E/A (No unit) & $1.34 \pm 0.43$ & $1.29(1.04-1.58)$ & $1.17 \pm 0.41$ & $1.10(0.87-1.38)$ & $1.07 \pm 0.40$ & $0.97(0.81-1.26)$ & $<0.0001$ \\
\hline $\begin{array}{l}\text { E wave Deceleration time (DT) } \\
\text { (ms) }\end{array}$ & $208.49 \pm 52.08$ & $206.25(170.47-241.98)$ & $210.47 \pm 54.00$ & $205.13(174.48-239.14)$ & $216.34 \pm 50.52$ & $211.68(184.10-247.57)$ & 0.21 \\
\hline $\mathbf{E}^{\prime}(\mathbf{c m} / \mathbf{s})$ & $13.06 \pm 3.20$ & $13.14(10.53-15.41)$ & $11.25 \pm 3.09$ & $10.75(9.17-13.00)$ & $10.06 \pm 3.02$ & $9.44(7.94-12.06)$ & $<0.0001$ \\
\hline E/E' (No unit) & $5.65 \pm 1.39$ & $5.48(4.71-6.39)$ & $6.52 \pm 1.61$ & $6.32(5.37-7.37)$ & $6.94 \pm 2.09$ & $6.58(5.65-7.85)$ & $<0.0001$ \\
\hline S/D PVF & $1.23 \pm 0.33$ & $1.19(1.02-1.41)$ & $1.38 \pm 0.37$ & $1.36(1.13-1.61)$ & $1.43 \pm 0.37$ & $1.38(1.18-1.67)$ & $<0.0001$ \\
\hline $\mathbf{E} / \mathbf{V p}$ & $1.41 \pm 0.57$ & $1.35(1.02-1.72)$ & $1.36 \pm 0.53$ & $1.34(1.02-1.66)$ & $1.16 \pm 0.54$ & $1.06(0.78-1.44)$ & $<0.0001$ \\
\hline IVRT (ms) & $77.20 \pm 17.80$ & $75.69(65.56-88.65)$ & $82.85 \pm 19.44$ & $81.89(69.95-95.73)$ & $90.01 \pm 20.06$ & $90.54(75.72-102.93)$ & $<0.0001$ \\
\hline $\begin{array}{l}\text { Tricuspid regurgitant velocity } \\
(\mathrm{m} / \mathrm{s})\end{array}$ & $2.11 \pm 0.29$ & $2.10(1.92-2.28)$ & $2.13 \pm 0.36$ & $2.17(1.97-2.36)$ & $2.16 \pm 0.31$ & $2.16(2.01-2.41)$ & 0.076 \\
\hline GSendo \% & $-23.83 \pm 2.62$ & $-23.87(-25.67--22.03)$ & $-23.23 \pm 2.73$ & $-23.33(-25.07--21.40)$ & $-22.84 \pm 2.75$ & $-22.57(-24.47--20.90)$ & $<0.0001$ \\
\hline GSfull-wall \% & $-21.46 \pm 2.42$ & $-21.53(-23.20--19.70)$ & $-20.99 \pm 2.56$ & $-21.07(-22.70--19.20)$ & $-20.58 \pm 2.48$ & $-20.27(-22.30--19.07)$ & 0.0004 \\
\hline GSepi \% & $-19.40 \pm 2.37$ & $-19.37(-21.03--17.70)$ & $-19.04 \pm 2.50$ & $-19.03(-20.80--17.27)$ & $-18.63 \pm 2.39$ & $-18.53(-20.20--17.17)$ & 0.007 \\
\hline GSendo/ GSepi ratio & $1.23 \pm 0.08$ & $1.22(1.18-1.27)$ & $1.23 \pm 0.08$ & $1.21(1.17-1.26)$ & $1.23 \pm 0.09$ & $1.21(1.17-1.27)$ & 0.13 \\
\hline GSendo Base-apex ratio & $0.67 \pm 0.11$ & $0.66(0.59-0.73)$ & $0.65 \pm 0.11$ & $0.65(0.57-0.72)$ & $0.66 \pm 0.13$ & $0.65(0.56-0.74)$ & 0.15 \\
\hline GSfull-wall Base- apex ratio & $0.81 \pm 0.13$ & $0.80(0.72-0.88)$ & $0.79 \pm 0.13$ & $0.78(0.69-0.87)$ & $0.80 \pm 0.15$ & $0.80(0.69-0.89)$ & 0.11 \\
\hline GSepi Base-apex ratio & $0.96 \pm 0.17$ & $0.94(0.84-1.06)$ & $0.93 \pm 0.18$ & $0.92(0.81-1.04)$ & $0.95 \pm 0.19$ & $0.94(0.83-1.07)$ & 0.068 \\
\hline GSRs $1 /$ sec & $-1.13 \pm 0.16$ & $-1.13(-1.23--1.00)$ & $-1.12 \pm 0.17$ & $-1.10(-1.23--1.00)$ & $-1.09 \pm 0.17$ & $-1.07(-1.20--1.00)$ & 0.024 \\
\hline GSRe 1/sec & $1.53 \pm 0.41$ & $1.53(1.27-1.80)$ & $1.32 \pm 0.34$ & $1.27(1.07-1.53)$ & $1.21 \pm 0.36$ & $1.17(0.97-1.43)$ & $<0.0001$ \\
\hline GSRa 1/sec & $0.79 \pm 0.25$ & $0.75(0.60-0.97)$ & $0.89 \pm 0.24$ & $0.90(0.73-1.03)$ & $0.92 \pm 0.23$ & $0.90(0.77-1.10)$ & $<0.0001$ \\
\hline
\end{tabular}

GSendo, Global subendocardial peak longitudinal strain; GSfull-wall, Global full-wall peak longitudinal strain; GSepi, Global subendocardial peak longitudinal strain; GSRs 1/sec, Global systolic peak longitudinal strain rate; GSRe 1/sec, Global early diastolic peak longitudinal strain rate; GSRa 1/sec, Global late diastolic peak longitudinal strain rate 